\title{
The influence of the soil constitutive models on the seismic analysis of pile-supported wharf structures with batter piles in cut-slope rock dike
}

https://doi.org/10.2478/sgem-2019-0050

received June 21, 2019; accepted May 7, 2020.

\begin{abstract}
In coastal regions, earthquakes caused severe damage to marine structures. Many researchers have conducted numerical investigations in order to understand the dynamic behavior of these structures. The most frequently used model in numerical calculations of soil is the linear-elastic perfectly plastic model with a MohrCoulomb failure criterion (MC model). It is recommended to use this model to represent a first-order approximation of soil behavior. Therefore, it is necessary to accommodate soil constitutive models for the specific geotechnical problems.
\end{abstract}

In this paper, three soil constitutive models with different accuracy were applied by using the twodimensional finite element software PLAXIS to study the behavior of pile-supported wharf embedded in rock dike, under the 1989 Loma Prieta earthquake. These models are: a linear-elastic perfectly plastic model (MC model), an elastoplastic model with isotropic hardening (HS model), and the Hardening Soil model with an extension to the small-strain stiffness (HSS model).

A typical pile-supported wharf structure with batter piles from the western United States ports was selected to perform the study. The wharf included cut-slope (sliver) rock dike configuration, which is constituted by a thin layer of rockfill overlaid by a slope of loose sand. The

*Corresponding author: Adam Hamrouni, Laboratory of Management, Maintenance and Rehabilitation Of Infrastructure (InfraRES), Mohamed-Cherif Messaadia University of Souk-Ahras, BP n ${ }^{\circ} 1553$, 41000 Souk-Ahras, Algeria, E-mail: hamrouni.adam@yahoo.fr Lylia Deghoul, Geomaterials, Environment and Planning Laboratory (LGEA), Mouloud MAMMERI University of Tizi-Ouzou (UMMTO), Civil Engineering Department, Faculty of Construction, Campus Hasnaoua, Tizi-Ouzou, 15000, Algeria

Smail Gabi, Geomaterials, Environment and Planning Laboratory (LGEA), Mouloud MAMMERI University of Tizi-Ouzou (UMMTO), Civil Engineering Department, Faculty of Construction, Campus Hasnaoua, Tizi-Ouzou, 15000, Algeria foundation soil and the backfill soil behind the wharf were all dense sand. The soil parameters used in the study were calibrated in numerical soil element tests (Oedometer and Triaxial tests).

The wharf displacement and pore pressure results obtained using models with different accuracy were compared to the numerical results of Heidary-Torkamani et al. ${ }^{[28]}$ It was found that the Hardening Soil model with small-strain stiffness (HSS model) gives clearly better results than the $\mathrm{MC}$ and $\mathrm{HS}$ models.

Afterwards, the pile displacements in sloping rockfill were analyzed. The displacement time histories of the rock dike at the top and at the toe were also exposed. It can be noted that during the earthquake there was a significant lateral ground displacement at the upper part of the embankment due to the liquefaction of loose sand. This movement caused displacement at the dike top greater than its displacement at the toe. Consequently, the behavior of the wharf was affected and the pile displacements were important, specially the piles closest to the dike top.

Keywords: iles; wharf; cut-slope rock dike; finite element analysis; seismic; soil constitutive models.

\section{Introduction}

In the past decades, seaports suffered large structural disorders, economic and social losses, mostly due to earthquakes. Among the damaged port structures are pile-supported wharves founded in sloping rockfill or through the rock dikes. These structures are commonly used worldwide, and have been the subject of several experimental and numerical studies. Yang ${ }^{[1]}$ has studied the seismic response of the Seventh Street Terminal Port of Oakland using FLAC software, ${ }^{[2]}$ and used some modifications to take into account the effect of sloping ground. Several dynamic centrifuge tests were conducted 
at the University of California, Davis (UCD). ${ }^{[3-10]}$ All centrifuge models represented case histories, consisting of rock dike configurations and wharf deck supported by piles. These tests were carried out in order to better understand the seismic performance of wharf piles. Hwang et al. ${ }^{[1]}$ performed shaking table model tests, to reproduce the dynamic behavior of a gravity quay wall and a pile-supported wharf damaged during the 1995 Kobe earthquake. The results of shaking table model tests were compared with the field measurements and with the results of the previous model testing. McCullough ${ }^{[3]}$ and Dickenson and McCullough ${ }^{[12]}$ presented centrifuge modeling results of pile supported wharves and pile in sloping rockfill. These results were used to validate two geotechnical seismic analysis methods: Newmark sliding block method, ${ }^{[13]}$ and numerical modeling using the finite difference code FLAC. ${ }^{[2]}$ The authors also performed a numerical analysis of the Seventh Street Terminal (Berths 35 through 38), at the Port of Oakland subjected to the 1989 Loma Prieta earthquake and compared the displacement results to in-situ observations. ${ }^{[14,15]}$ Takahashi and Takemura ${ }^{[16]}$ carried out a centrifuge model test of the Takahama Wharf damaged during the 1995 Hyogo-ken Nambu earthquake, and performed a parametric study to establish the effect of the thickness of the liquefiable sand layer on the results, and to study the piled deck-caisson dynamic interaction. Dickenson et al. ${ }^{[17]}$ provided a synthesis of modeling considerations and summary of the 2D FLAC numerical modeling results of the Berth 404 at Pier 400 of Port of Los Angeles, and considered pile-deck connections and pile-rockfill interaction. The results were validated with the case history data and the results from large-scale tests. Huertas and Romanel ${ }^{[18]}$ investigated the coupled hydro-mechanical behavior of soils and studied the influence of the liquefaction on the stability of pile supported wharf in rockfill dike, considering the nonlinear elasto-plastic constitutive model UBCSand. Dickenson et al. ${ }^{[19]}$ investigated the seismic performance of pile-supported wharves subjected to long-duration ground motions and considered the evaluation of kinematic loads on pile and soil-pile interaction in rockfill dikes. Su et al. ${ }^{[20]}$ conducted 3D finite element analysis of pile-supported wharf and considered the effect of the ground slope and pile connectivity along the wharf deck. Souri et al. ${ }^{[21]}$ conducted physical modeling of wharf piles in sloping rockfill subjected to liquefaction-induced lateral spreading, and studied kinematic demands and full superstructure inertia in order to estimate bending moments of piles at different depths. Vytiniotis et al. ${ }^{[22]}$ studied the effect of prefabricated vertical drains installed behind the crest of the slope to control the lateral spreading in the fill and to reduce seismic damage of the wharf structure.

Recently, a large volume of research works used seismic fragility curves as a useful tool to evaluate the seismic performance of pile-supported wharves. ${ }^{[23-30]}$

Several port structures use batter piles to providelateral resistance and to limit deflections from lateral loads, such as ship berthing and seismic loads. In the past, engineers contest the use of batter piles due to the poor performance under earthquake, caused by the lack of proper design of the batter piles head connections. Actually, by resolving this problem, batter piles have smaller deformations than vertical ones. Roth et al. ${ }^{[31]}$ studied the role of batter piles in the seismic performance of wharves. Schlechter et al. ${ }^{[32]}$ carried out a series of large-scale centrifuge models, with and without batter piles of typical pile-supported wharf configurations. Razavi et al. ${ }^{[33]}$ presented some batter pile damages during severe earthquakes, and performed seismic analysis of a typical pier with and without batter piles. Heidary-Torkamani et al. ${ }^{[28,29]}$ developed the seismic fragility curves of wharves with batter piles, considering different engineering demand parameters (EDPs) for each damage state, and also performed a sensitivity analysis in order to evaluate the influence of geotechnical parameter uncertainties in the seismic performance of the wharves. Li et al. ${ }^{[34,35]}$ ) studied dynamic response characteristics and failure process of vertical and batter pile-supported wharf structure, established on the same conditions, and subjected to two different earthquake levels.

The soil is a complex material and exhibits nonlinearly behavior when it is subjected to very low strain levels Atkinson and Sallfors, ${ }^{[36]}$ as for example, far-field deformations around deep excavation and tunnel, and soils subjected to seismic ground motion. Researchers developed different soil constitutive models with various degrees of complexity, and it is important to choose the most representative soil behavior model, as it has a significant impact on the results.

A great amount of investigation was conducted to determine the influence of soil constitutive models at small-strain levels for soils around deep excavation and tunnel; however, less researches were done in the case of soils under seismic loading. Truty ${ }^{[37]}$ studied the deformations near the excavations in Berlin sand, using Mohr-Coulomb (MC), Hardening Soil (HS) and Hardening Soil with Small-strain stiffness (HSS) models, and presented the soil deformation, the bending moment and the deflection of the wall. Hamrouni et al. ${ }^{[38]}$ highlighted the impact of soil constitutive models on the prediction of the displacements of the surrounding soil in the execution of a shallow tunnel. Benz et al. ${ }^{[39]}$ described soil stiffness 
at small-strains and presented the available smallstrain stiffness models. The authors also performed four numerical applications on: triaxial test, spread footing problem and excavation problem 2D and 3D, using the finite element method with and without small-strain stiffness formulation. Obrzud ${ }^{[40]}$ presented Hardening Soil standard and Hardening Soil Small-strain models in finite element program, and exposed the comparison result with Mohr-Coulomb modeling of excavation in Berlin sand, tunneling and shallow footing in Texas sand. Besseling ${ }^{[4]]}$ evaluated the sensitivity of the site response to variation of the soil constitutive models. Four soil constitutive models implemented in PLAXIS software were considered: the linear elastic (LE), the Mohr-Coulomb (MC), the Hardening Soil (HS) and the Hardening Soil with Smallstrain stiffness (HSS) models. Based on the comparison of site responses, the HSS model was adopted for modeling of the soil deposit in the study of the dynamic jetty analysis. Vakili et al. ${ }^{[42]}$ presented the numerical approach for adaptive constitutive modeling of soils using the finite element method, and gave results using this approach in numerical soil element tests (Oedometer and Triaxial tests) and staged tunneling construction. Vakili et al. ${ }^{[43]}$ evaluated the results for the vertical displacements of four selected nodes in shallow and deep tunnel projects using three soil constitutive models. Op de Kelder ${ }^{[44]}$ analyzed the horizontal deformations on the sheet pile wall as a result of excavation of a building pit, using the Hardening Soil and the Hardening Soil Small strain stiffness models implemented in the FE code PLAXIS 2D. For the calculation of shear modulus at very small strains $\left(G_{0}\right)$ and the threshold shear strain $\left(\gamma_{0,7}\right)$ of HSS model, the author employed the correlation of Alpan ${ }^{[45]}$ and the correlation of Benz and Vermeer. ${ }^{[46]}$ Thereafter, the obtained numerical results were compared to the inclinometer measurements. $\operatorname{Alpan}^{[45]}$ gave curves that describe the relationship between static $E_{\text {stat }}$ (large-strain) and dynamic $E_{d y n}$ (smallstrain) stiffness moduli $\left(E_{\text {stat }}\right.$ with $\left.E_{d y n}=E_{0}\right)$. $E_{0}$ is the Young's modulus at very small strains. According to Wichtmann and Triantafyllidis, ${ }^{[4]}$ it can be assumed that the correlation of Alpan estimated $E_{\text {stat }}$ by the stiffness during first loading $E_{50}\left(E_{\text {stat }}=E_{50}\right)$. For the correlation of Benz and Vermeer, it is recommended to interpret $E_{\text {stat }}$ as the secant modulus during large unloading and reloading cycle $E_{u r}\left(E_{s t a t}=E_{u r}\right.$ $\left.=3 E_{50}\right)$. Szerző and Batali ${ }^{[48]}$ used different constitutive laws for the soil and interface elements to analyze the numerical settlement results of piled raft foundations supporting a circular gas tank, and compared these to field measurements and two simplified methods: the Poulos-Davis-Randolph method ${ }^{[49]}$ and the Piglet software. ${ }^{[50]}$ Akbari Hamed ${ }^{[51]}$ compared the experimental results of
Triaxial and Oedometer tests to the numerical results in two finite element software, using various soil constitutive models, and also performed a comparison between the measured data and the numerical analysis results of the asphaltic core rockfill dam (Dam-X, Quebec). Yeganeh and Fatahi ${ }^{[52]}$ examined the effects of soil plasticity type and soil-structure interaction in the seismic analyses of the typical high rise buildings, constituted by 20-story reinforced concrete moment-resisting building with a mat foundation, using the explicit finite difference program FLAC3D.

Considering the few researches to evaluate the impact of choosing soil constitutive model on the seismic results and, in addition to the complexity of seismic behavior of wharf structures with batter piles in sloping rockfill, this study aimed to capture the more realistic seismic behavior of pile-supported wharf with batter piles in cut-slope rock dike. For this, three soil constitutive models with increasing levels of complexity were considered using finite element method. The techniques of the finite element modeling will be given in the following sections.

\section{Finite element analyses}

A two-dimensional finite element modeling was generated using the software PLAXIS 2D. ${ }^{[53]}$ The details of the modeling adopted in the dynamic analysis are listed below:

The geometry model boundaries are taken relatively far away to avoid direct influence of the boundary conditions Hamrouni et al. ${ }^{[54]}$ Horizontal fixity has been introduced at the vertical boundaries, while the bottom boundary of the model has been subjected to total fixity (both horizontal and vertical fixities).

A prescribed displacement is selected at the bottom boundary of the model in order to simulate the dynamic loading. Standard earthquake boundaries are specified at the right and left side of the model geometry, to avoid the reflection of the seismic waves on the model boundaries and perturbations. ${ }^{[55]}$ The relaxation coefficients $C_{1}$ and $C_{2}$ were kept in default values 1 and 0.25 , respectively.

The mesh coarseness was fine and refined around the dike with 15 node triangular elements. The influence of the mesh must be tested for each analysis. In Plaxis, ${ }^{[56]}$ the Average Element Size (AES) is calculated from the outer geometry dimensions $\left(x_{\min }, x_{\max }, y_{\min }, y_{\max }\right)$ and the number of generated triangular elements $\left(n_{c}\right)$, as presented in equation (1): 


$$
A E S=\left[\left(x_{\max }-x_{\min }\right)\left(y_{\max }-y_{\min }\right) / n_{c}\right]^{0.5}
$$

Kuhlemeyer and Lysmer ${ }^{[57]}$ provided a guideline to use AES, which must be smaller than approximately onetenth to one-eighth of the wavelength $(\lambda)$ associated with the highest frequency of the input wave, equation (2):

$$
A E S \leq \frac{\lambda}{10} \text { to } \frac{\lambda}{8}
$$

The equation for the time-dependent movement of a system is shown in equation (3):

$$
[M] \ddot{U}+[C] \dot{U}+[K] U=F(t)
$$

Here, $[M],[C]$ and $[N]$ are respectively the mass, the damping and the stiffness matrices. $F(t)$ is the external force vector applied on the system. The displacement $(U)$, the velocity $(\dot{U})$ and the acceleration $(\ddot{U})$ can vary with time.

The damping matrix $[C]$ of the system is proportional to the mass $[M]$ and stiffness $[K]$ matrices by means of Rayleigh coefficients, $\alpha_{R}$ and $\beta_{R}{ }^{[58,59]}$ as presented in equation (4):

$$
[C]=\alpha_{R}[M]+\beta_{R}[K]
$$

PLAXIS 2D uses implicit time integration based on the Newmark scheme. ${ }^{[60]}$ The displacement and the velocity at the point in time $t+d t$ are expressed respectively in equations (5) and (6), where $d t$ is the time step, $\alpha_{N}$ and $\beta_{N}$ are the Newmark coefficients that determine the accuracy of the numerical time integration:

$$
\begin{gathered}
U^{t+d t}=U^{t}+\dot{U}^{t} d t+\left(\left(\frac{1}{2}-\alpha_{N}\right) \ddot{U}^{t}+\alpha_{N} \ddot{U}^{t+d t}\right) d t^{2} \\
\dot{U}^{t+d t}=\dot{U}^{t}+\left(\left(1-\beta_{N}\right) \ddot{U}^{t}+\beta_{N} \ddot{U}^{t+d t}\right) d t
\end{gathered}
$$

In order to obtain a stable solution, the following condition in equations (7) and (8) must apply:

$$
\begin{gathered}
\beta_{N} \geq 0,5 \\
\alpha_{N} \geq \frac{1}{4}\left(\frac{1}{2}+\beta_{N}\right)^{2}
\end{gathered}
$$

However, during the last two decades, new and more accurate numerical methods have been developed. For example, the $\alpha$-method (or HHT method), ${ }^{[61]}$ that uses the Newmark scheme to solve the modified equations of motion shown in equation (9):

$$
\begin{gathered}
M \ddot{U}^{t}+(1-\alpha) C \dot{U}^{t}+(1-\alpha) K U^{t}=(1-\alpha) F^{t}+ \\
+\alpha F^{t}-\alpha C \dot{U}^{t-d t}-\alpha K U^{t-d t}
\end{gathered}
$$

The numerical parameters $\alpha, \alpha_{N}$ and $\beta_{N}$ are selected such as in the following equations (10), (11) and (12) in order to obtain stable and accurate results:

$$
\begin{aligned}
& 0 \leq \alpha \leq \frac{1}{3} \\
& \alpha_{N}=\frac{(1+\alpha)^{2}}{4} \\
& \beta_{N}=\frac{1}{2}+\alpha
\end{aligned}
$$

For a damped Newmark integration scheme $(\alpha>0)$, the Rayleigh coefficient $\beta_{R}$ should be reduced by the quantity $\alpha . d t^{[62]}$

The standard setting of the PLAXIS code for time integration is the damped Newmark scheme with $\alpha_{N}=$ 0.3025 and $\beta_{N}=0.6$, that corresponds to $\alpha=0.1$.

The time step used in a calculation is constant and it is presented in equation (13):

$$
d t=\frac{\Delta t}{n \cdot m}
$$

Where $\Delta t$ is the duration of the dynamic loading, $m$ is the max steps number (number of additional steps) and $n$ is the number of sub steps (dynamic sub step). The upper limit of the max steps number is given equal to 10,000, and PLAXIS automatically calculates the number of sub steps. In order to visualize the complete signal, it is advised to use $m$ equals the number of multipliers that defines the input signal and $n$ equals $1 .{ }^{[63,64]}$

To avoid unreliable numerical response in a finite element model, a careful evaluation of the critical time step $d t_{\text {crit }}$ for the system should be executed. ${ }^{[5,62]}$

\section{Model geometry description}

The configuration of the wharf chosen for this study is the JCB01 model, ${ }^{[10]}$ selected from a series of centrifuge models carried out at the Center for Geotechnical Modeling of California University, Davis Campus (UC Davis).

This model consists of a wharf deck supported by seven rows of vertical piles included two pairs of batter piles, embedded in cut slope rock dike configuration. The dike is constructed by a thin layer of rockfill overlaid by a slope of loose sand ( $40 \%$ relative density). The side slope was 2 horizontal to 1 vertical (2:1). The foundation soils and backfill soil behind the wharf were all dense $(74 \%$ relative density). The soil and structural geometry are shown in Fig. 1. 


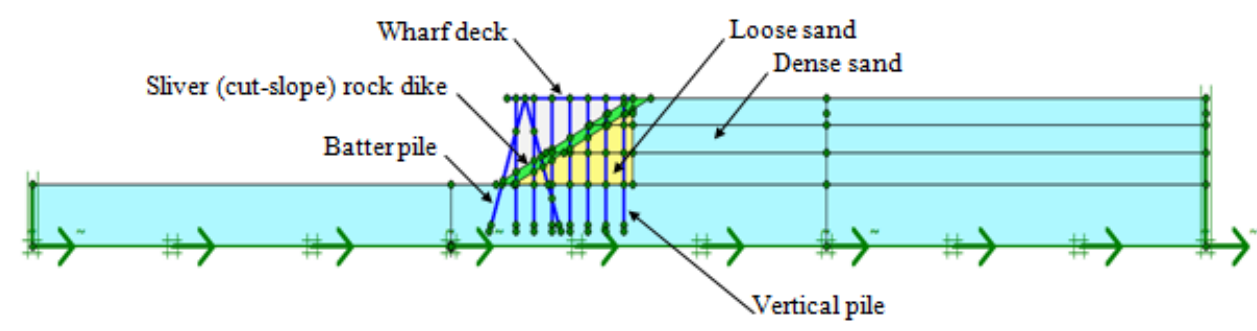

Figure 1: Finite element model of the wharf.

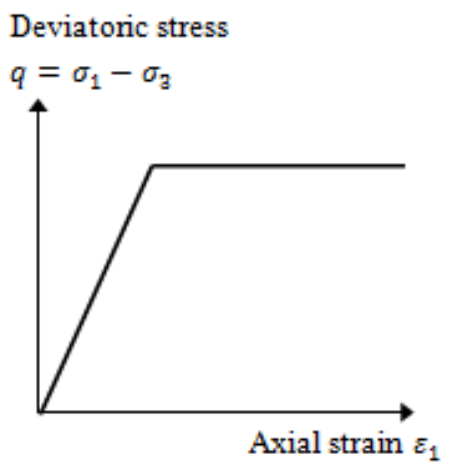

(1)

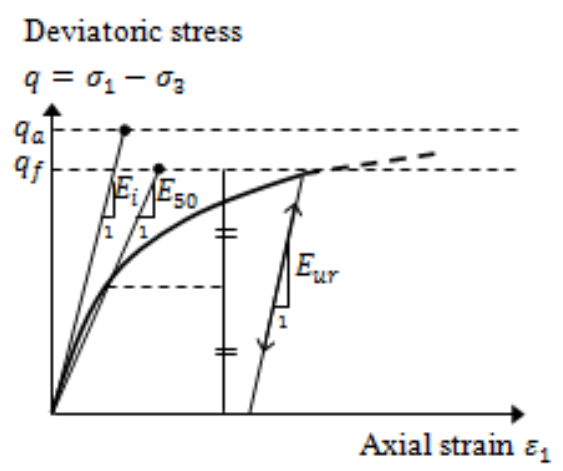

(2)

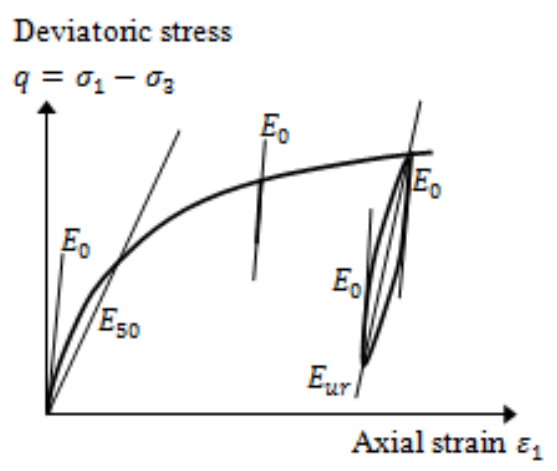

(3)

Figure 2: Stiffness parameters of standard drained triaxial test results: (1) for the MC model, (2) for the HS model, (3) for the HSS model [66]

\section{Material properties}

In numerical analysis, material behavior of the soils and structural elements are represented by material constitutive models.

\subsection{Material model for soils and rockfill}

The sandy soils used in the centrifuge model were Nevada sand.$^{[65]}$ The rock was imported from a quarry on Catalina Island, off the coast of southern California, and crushed to an appropriate size in order to represent the rock-pile interaction.

The geotechnical parameter values used in numerical modeling are presented below according to the three soil constitutive models applied in this study:

\subsubsection{Mohr-Coulomb model (MC model)}

The most common material model used is the linear-elastic perfectly plastic model (Mohr-Coulomb model). It requires only five input parameters: Young's modulus $E$, Poisson's ratio $v$, friction angle $\varphi$, cohesion $C$ and dilatancy angle $\psi \cdot{ }^{[66]}$ The stress-strain relationship is considered as elasticperfectly plastic (Fig. 2(1)).

The soil is composed of granular particles, and is generally modeled in numerical analysis as a continuum. The individual particle size of the soil is in the order of 30 to 40 times less than the pile diameter or the dimensions of the foundation. In the case of rockfill used in the marine structures, the median rockfill size was 2.5 to 3 times smaller than the pile diameter. Then, the rock particles act as individual particles and less as a continuum. Diaz et al. ${ }^{[67]}$ introduced a concept of pseudo cohesion in rockfill so as to modify the modeled continuum behavior to match the measured behavior. McCullough ${ }^{[3]}$ added 15 $\mathrm{kPa}$ pseudo-cohesion for the rockfill in order to consider the individual rock particle interaction with the pile and took into account the difference between upslope and downslope spring stiffness. This concept was also adopted by Martin, ${ }^{[68]}$ and McCullough and Dickenson. ${ }^{[69]}$ Kawamata ${ }^{[70]}$ considered the lateral reaction of the rockfill as a combination of reactions due to both friction and interlocking between large rock particles.

The FE code PLAXIS can handle cohesionless soils with cohesion equal to zero, but some options do not perform well. The material models manual of PLAXIS ${ }^{[7]}$ advises to enter at least a small value of cohesion (use $C$ > 
Table 1: Soil parameters used for the MC model.

\begin{tabular}{lllll}
\hline Parameters & Unit & Dense sand & Loose sand & Rockfill \\
\hline $\boldsymbol{\varphi}$ & $\circ$ & 37 & 33.2 & 45 \\
$\boldsymbol{\psi}$ & $\circ$ & 21 & 7 & 0 \\
$\boldsymbol{C}$ & $\mathrm{kN} / \mathrm{m}^{2}$ & 0.5 & 0.5 & 15 \\
$\boldsymbol{v}$ & - & 0.3 & 0.3 & 0.2 \\
$\boldsymbol{E}$ & $\mathrm{kN} / \mathrm{m}^{2}$ & $6.032 \times 10^{4}$ & $1.638 \times 10^{4}$ & $2.232 \times 10^{4}$ \\
\hline
\end{tabular}

Table 2 - Soil parameters used for HS model

\begin{tabular}{lllll}
\hline Parameters & Unit & Dense sand & Loose sand & Rockfill \\
\hline$E_{50}^{r e f}$ & $\mathrm{kN} / \mathrm{m}^{2}$ & $6.032 \times 10^{4}$ & $1.638 \times 10^{4}$ & $2.232 \times 10^{4}$ \\
$E_{\text {oed }}^{r e f}$ & $\mathrm{kN} / \mathrm{m}^{2}$ & $4.826 \times 10^{4}$ & $1.310 \times 10^{4}$ & $1.786 \times 10^{4}$ \\
$E_{\text {ur }}^{r e f}$ & $\mathrm{kN} / \mathrm{m}^{2}$ & $1.810 \times 10^{4}$ & $4.914 \times 10^{4}$ & $6.696 \times 10^{4}$ \\
$\boldsymbol{P}^{r e f}$ & $\mathrm{kN} / \mathrm{m}^{2}$ & 100 & 100 & 100 \\
$\boldsymbol{M}$ & - & 0.5 & 0.5 & 0.5 \\
$\boldsymbol{K}_{0}{ }^{n c}$ & - & 0.3982 & 0.4524 & 0.2929 \\
$\boldsymbol{R}_{f}$ & - & 0.9 & 0.9 & 0.9 \\
\hline
\end{tabular}

$0.2 \mathrm{kPa}$ ). So, in this work, cohesion of the dense and loose sand is chosen equal to 0.5. For the rockfill, an artificial cohesion of $15 \mathrm{kPa}$ and a dilation angle of $0^{\circ}$ were applied. [3]

The input parameters of soil used for the MohrCoulomb model are summarized in Table 1, and for more details refer to Boland et al., ${ }^{[10]}$ McCullough,, ${ }^{[3]}$ HeidaryTorkamani et al. ${ }^{[28,29]}$ and Amirabadi et al. ${ }^{[26]}$

The dry mass density was $1633 \mathrm{~kg} / \mathrm{m}^{3}, 1522 \mathrm{~kg} / \mathrm{m}^{3}$ and $1611 \mathrm{~kg} / \mathrm{m}^{3}$ respectively for dense sand, loose sand and rockfill. The material damping of soils was simulated with $5 \%$ of damping ratio (Rayleigh damping).

The permeability was $0.043 \times 10^{-3} \mathrm{~m} / \mathrm{s}, 0.066 \times 10^{-3} \mathrm{~m} / \mathrm{s}$ and $0.01 \mathrm{~m} / \mathrm{s}$ respectively for dense sand, loose sand and rockfill. For water conditions, the ground was saturated. A water depth of $12.4 \mathrm{~m}$, and volumetric weight of $10.3 \mathrm{kN} / \mathrm{m}^{3}$ (salted water) were defined.

\subsubsection{Hardening Soil model (HS model)}

The Hardening Soil model, developed by Schanz et al., ${ }^{[72]}$ describes a hyperbolic stress - strain curve (Fig. 2(2)). It has the same failure criterion as the Mohr-Coulomb model and uses three types of soil stiffness for three loading conditions, namely triaxial loading, oedometer loading and unloading/reloading, as presented in equations (14), (15) and (16):

$$
\begin{gathered}
E_{50}=E_{50}^{r e f}\left(\frac{c \cos \varphi-\sigma_{3}^{\prime} \sin \varphi}{c \cos \varphi+p^{r e f} \sin \varphi}\right)^{m} \\
E_{\text {oed }}=E_{\text {oed }}^{r e f}\left(\frac{c \cos \varphi-\sigma_{3}^{\prime} \sin \varphi}{c \cos \varphi+p^{r e f} \sin \varphi}\right)^{m} \\
E_{\text {ur }}=E_{\text {ur }}^{r e f}\left(\frac{c \cos \varphi-\sigma_{3}^{\prime} \sin \varphi}{c \cos \varphi+P^{r e f} \sin \varphi}\right)^{m}
\end{gathered}
$$

where the $E_{50}^{r e f}, E_{\text {oed }}^{r e f}$ and $E_{u r}^{r e f}$ represent the stiffness at the reference pressure $P^{r e f}$ (at default setting $P^{r e f}$ equals 100 $\left.\mathrm{kN} / \mathrm{m}^{2}\right) . \sigma_{3}$ is the effective confining pressure in Triaxial test, it is negative for compression. ${ }^{[73]}$ The amount of stress dependency is given by the power $m$.

The HS model was implemented into PLAXIS finite element code. In many practical cases, it is appropriate to determine the stiffness moduli by using the default setting of PLAXIS: $E_{50}^{\text {ref }}$ is equal to the Young's modulus defined in the Mohr Coulomb model, $E_{50}^{\text {ref }}=1.25 E_{\text {oed }}^{\text {ref }}$ and $E_{u r}^{\text {ref }}=3$ $E_{50}^{\text {ref }}$ [71]

The soil parameters required in the Hardening Soil model for the materials used in this study, in addition to the soil parameters of MC model, are presented in Table 2.

\subsubsection{Hardening Soil Small-strain model (HSS model)}

The Hardening Soil model with small-strain stiffness is a modification of the Hardening Soil model. It takes account the degradation of shear stiffness with shear strain during loading (developed by Benz, 2007). [74]

The model's stiffness parameters in a triaxial test were presented in Fig. 2(3). The stress-strain curve for small-strains was described by a simple hyperbolic law, analogous to the hyperbolic law for larger strains. ${ }^{\text {[75] }}$

The HSS model uses almost entirely the same parameters as HS model, except two additional parameters: The initial or very small-strain shear modulus $G_{0}$, and the shear strain level $\gamma_{0,7}$ at which the secant shear modulus $G_{\mathrm{S}}$ degrades to about $72 \%$ of initial shear modulus $G_{0}$.

Several works have demonstrated that when increasing strain amplitude, soil stiffness decays nonlinearly. ${ }^{[36]}$ The stiffness reduction curves exhibit a characteristic S-shape in logarithmic scale (Fig. 3), only at very small-strain levels (less than $10^{-6}$ ) where the soil describes linear elastic behavior.

The stress dependency is given by the following equation (17). $G_{0}{ }^{r e f}$ is the reference shear modulus at very small-strains $\left(\varepsilon<10^{-6}\right)$. 


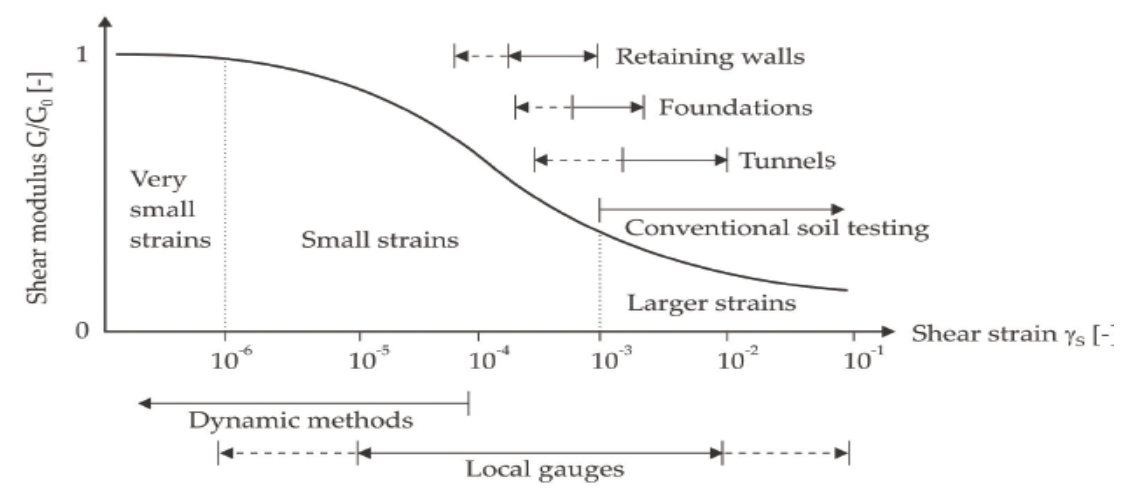

Figure 3: Characteristic stiffness-strain behavior in logarithmic scale (after Atkinson and Sallfors ${ }^{[36]}$ and Mair ${ }^{[76]}$ ) (Atkinson, 2000) ${ }^{[77]}$.

$$
G_{0}=G_{0}^{r e f}\left(\frac{c \cos \varphi-\sigma_{3}^{\prime} \sin \varphi}{c \cos \varphi+p^{r e f} \sin \varphi}\right)^{m}
$$

The very small-strain shear modulus $G_{0}$ of non-cohesive soils can be determined using different methods, with different efforts and accuracy. ${ }^{[47]}$ In the absence of experimental data for the determination of $G_{0}$ parameter, approximations from empirical equations can be appropriate using the relation given by Hardin and Black ${ }^{[78]}$ (equation (18). Similarly, in the lack of experimental data for the determination of the threshold shear strain $\gamma_{0,7}$ correlations are also available, for example, a correlation between the threshold shear strain $\gamma_{0,7}$ and the Plasticity Index PI, ${ }^{[79]}$ or using the relationship of Hardin-Drnevich ${ }^{[80]}$ as shown in equation (19):

$$
\begin{gathered}
G_{0}^{r e f}=\frac{33(2.97-e)^{2}}{1+e}(M P a) \\
\gamma_{0,7} \approx \frac{1}{9 G_{0}}\left[2 c^{\prime}\left(1+\cos \left(2 \varphi^{\prime}\right)\right)-\sigma_{1}^{\prime}\left(1+K_{0}\right) \sin \left(2 \varphi^{\prime}\right)\right]
\end{gathered}
$$

where $K_{0}$ is the earth pressure coefficient at rest, and $\sigma_{1}$ 'is the effective vertical stress (negative pressure).

In dynamic applications, the HSS model introduces hysteric material damping and shows a typical hysteretic behavior (Ishihara, 1996), ${ }^{[81]}$ in contrast to the Hardening Soil model.

The values of the two additional soil parameters $G_{0}$ ref and $\gamma_{0,7}$ used in this analysis are presented in Table 3:

\subsection{Calibration of soil constitutive parameters in numerical soil element tests}

The constitutive parameters of the MC model have to be calibrated to advanced models, using two soil element tests available in the two-dimensional finite element code PLAXIS. These tests are Oedometer test (one-dimensional
Table 3: Additional input parameters of HSS model.

\begin{tabular}{lcccc}
\hline Parameters & Unit & Dense sand & Loose sand & Rockfill \\
\hline$\gamma_{0.7}$ & - & $4.918 \times 10^{-4}$ & $3.629 \times 10^{-4}$ & $4.246 \times 10^{-4}$ \\
$G_{0}{ }^{r e f}$ & $\mathrm{kN} / \mathrm{m}^{2}$ & $1.051 \times 10^{5}$ & $9.108 \times 10^{4}$ & $1.038 \times 10^{5}$ \\
\hline
\end{tabular}

compression) and Triaxial test. The following conditions are adopted:

- In the Oedometer test, the soil sample is subjected to four phases: two loading phases from 0 to $100 \mathrm{kPa}$ and

- $200 \mathrm{kPa}$, followed by two unloading phases to 100 $\mathrm{kPa}$ and $50 \mathrm{kPa}$.

- In Triaxial test, a confining pressure $\sigma_{3}$ of $100 \mathrm{kPa}$ is applied.

The calibration is limited to the variation of elasticity modulus $(E)$ for the MC model, which takes the values of stress dependent moduli of elasticity in the HSS model ( $E_{50}^{r e f}=1.25 E_{\text {oed }}^{r e f}, E_{\text {ur }}^{r e f}$ and $E_{0}^{\text {ref }}$, where $E_{0}^{\text {ref }}$ is the Young's modulus at very small-strain at the reference pressure $\mathrm{P}^{\text {ref }}$ ). The results of soil parameter calibrations in Oedometer and Triaxial tests are shown in Fig. 4.

According to the comparison between curves for both Oedometer and Triaxial tests, and for all the different soil materials, the best consistency between MC model and advanced models is observed when the value of the Young's modulus in the MC model is assumed to be equal to $E_{50}^{r e f}$. Consequently, all the geotechnical characteristics of the soil layers presented previously will be used in the numerical analysis. 


\subsection{Material model for structural elements}

The structural elements of the JCB01 centrifuge model were made from aluminum section. The piles were modeled using aluminum (6061-T6) tubing that has $0.636 \mathrm{~m}$ diameter, $0.0508 \mathrm{~m}$ wall thickness and $70 \mathrm{GPa}$ modulus of elasticity. The wharf deck has $28.1 \mathrm{~m}$ transverse length, 12 $\mathrm{m}$ longitudinal length, $0.255 \mathrm{~m}$ thickness and $27.23 \mathrm{kN} / \mathrm{m}^{3}$ density. More properties were given in Boland et al. ${ }^{[10]}$ and McCullough. ${ }^{[3]}$

The main problem when modeling with PLAXIS 2D is the transition from three to two dimensions. Then, the wharf deck supported by three rows of piles was modeled as plane strain. The row of piles was transformed into continuous wall elements defined per meter length, called plane strain piles ( $p s p$ ). This method of modeling of piles in a 2D plane strain model is commonly used in piled raft foundations. ${ }^{[82-84]}$

The normal stiffness for plane strain pile $\left(E A_{p s p}\right)$, the flexural rigidity for plane strain pile $\left(E I_{p s p}\right)$ and the weight for plane strain pile $\left(w_{p s p}\right)$ can be calculated by using respectively the equations (20), (21) and (22):

$$
\begin{aligned}
E A_{p s p} & =E A_{p} \frac{n_{p-\text { row } i}}{L_{r}} \\
E I_{p s p} & =E I_{p} \frac{n_{p-\text { row } i}}{L_{r}} \\
w_{p s p} & =w_{p} \frac{n_{p-\text { row } i}}{L_{r}}
\end{aligned}
$$

where $E A_{p}$ is the normal stiffness for one pile, $A_{p}$ is the area of pile cross section, $E$ is the pile Young's modulus, $E I_{p}$ is the flexural rigidity for one pile, $I_{p}$ is the moment of inertia of pile, $w_{p}$ is the weight for one pile, $L_{r}$ is the pile spacing and $\left.n_{p \text {-row } i}\right)$ is the number of piles in the row $i$.

In this work, the material behavior of the structural elements (pile and wharf deck) is considered to be linear elastic and modeled by using plate elements. Interaction between ground (soils, rockfill) and plane strain piles is described using interface elements.

The material of the interface element could be modeled by a new material, which has the same strength properties of the surrounding soil (or rockfill) multiplied by a factor, called strength reducing factor for interface $R_{\text {int }}$, as expressed in equations (23) and (24). In the most cases, $R_{\text {int }}$ equals $2 / 3$. The proprieties of this new material were defined with Mohr Coulomb model.

$$
\begin{gathered}
C_{i}=R_{\text {int }} C_{\text {soil }} \\
\tan \left(\varphi_{i}\right)=R_{\text {int }} \tan \left(\varphi_{\text {soil }}\right)
\end{gathered}
$$

Table 4: Pile and deck properties.

\begin{tabular}{llll}
\hline Parameters & Unit & Pile & Deck \\
\hline EA & $\mathrm{kN} / \mathrm{m}$ & $162.75 \times 10^{4}$ & $17.85 \times 10^{6}$ \\
$\boldsymbol{E I}$ & $\mathrm{kN} \cdot \mathrm{m}^{2} / \mathrm{m}$ & $70.49 \times 10^{3}$ & $96.724 \times 10^{3}$ \\
$\boldsymbol{w}$ & $\mathrm{kN} / \mathrm{m} / \mathrm{m}$ & 0.633 & 6.9436 \\
$\boldsymbol{v}$ & - & 0.2 & 0.2 \\
\hline
\end{tabular}

where $C_{i}$ and $\varphi_{i}$ are respectively the cohesion and friction angle of the interface element, $C_{\text {soil }}$ and $\varphi_{\text {soil }}$ are respectively the cohesion and friction angle of the surrounding soil.

The input parameters used in the modeling of the structural elements are presented in Table 4. For more details, refer to studies by Boland et al., ${ }^{[10]}$ McCullough, ${ }^{[3]}$ Heidary-Torkamani et al., ${ }^{[28,29]}$ and Amirabadi et al. ${ }^{[26]}$

\section{Earthquake motion modeling}

The numerical model is subjected to the 1989 Loma Prieta earthquake time history recorded at the Oakland Outer Harbor Station (Fig. 5):

\section{Validation of the numerical analysis}

In order to verify the numerical model using the finite element method of the PLAXIS 2D, the displacement of soils around the rock dike and the pore pressure are determined and compared to the numerical results predicted using the two-dimensional finite difference of the code FLAC. ${ }^{[28]}$

The results of the total displacement of soils around the cut-slope rock dike for the three soil constitutive models are presented in Fig. 6, 7 and 8, respectively, for MC, HS and HSS models.

The maximum total displacement of soil observed for all three soil used constitutive models is located in the upper part of the loose sand embankment. The value of this maximum total displacement is obtained between $0.14 \mathrm{~m}$ and $0.15 \mathrm{~m}$ with MC and HS models, and between $0.08 \mathrm{~m}$ and $0.09 \mathrm{~m}$ with HSS model.

Heidary-Torkamani et al. ${ }^{[28]}$ have obtained 0.08973 $\mathrm{m}$ for the maximum vector displacement (Fig. 9). This displacement isincluded in theinterval of the displacement determined with HSS model. It can be concluded that the 


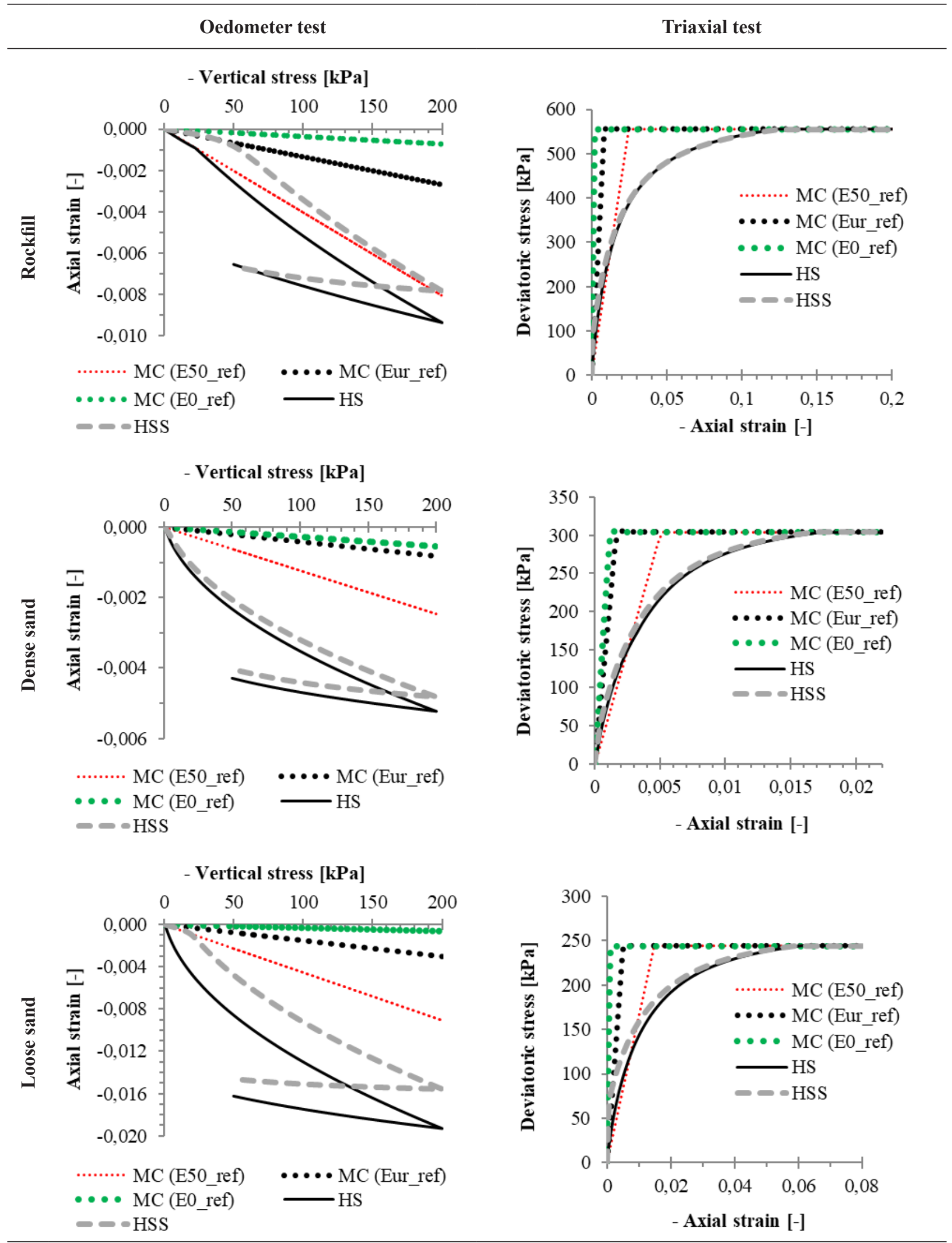

Figure 4: Calibration of soil parameters of MC model in numerical soil element tests for rockfill, dense sand and loose sand. 


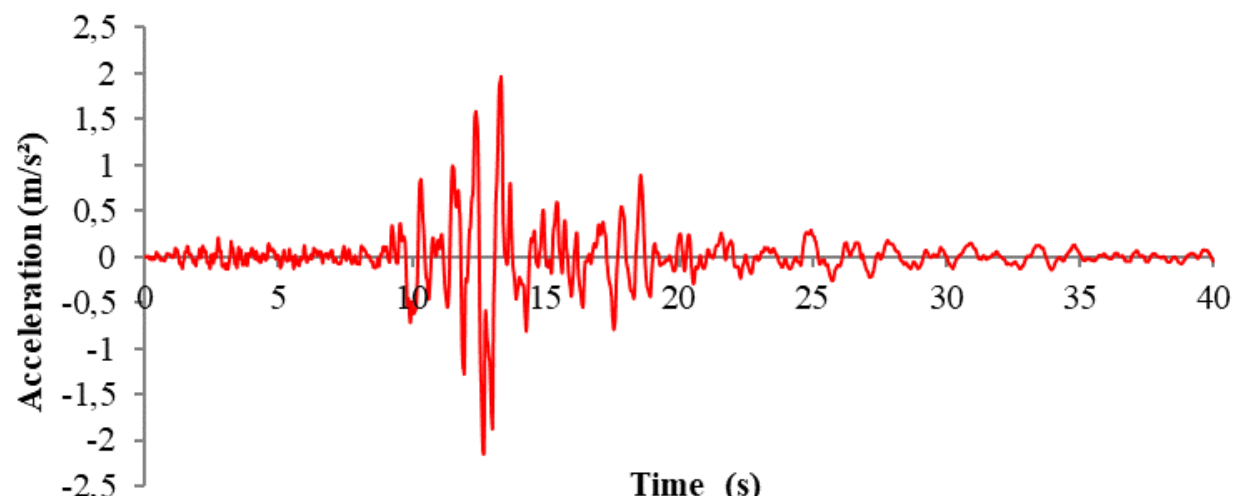

Figure 5: Unscaled input accelerogram from 1989 Loma Prieta earthquake.

results obtained from a 2D plane strain model (as seen in the paragraph 4.3 above), by using the HSS model give adequate results for soil and wharf displacements.

Concerning the pore pressure contour results obtained in the numerical model with PLAXIS 2D, the contours have the same shape for all three soil used constitutive models. So, it was plotted here with just one pore pressure contours (Fig. 10). The pore pressure around the zone of embedded pile is approximately 0.2 MPa. This result coincides with the total pore pressure contours presented by Heidary-Torkamani et al. ${ }^{[28]}$ in Fig. 11.

It can be justified that when the soils are subjected to dynamic loading, the MC, HS and HSS models of the finite element code PLAXIS 2D and the MC model of the finite difference code FLAC $2 \mathrm{D}^{[28]}$ give the same pore pressures, due to the fact that, all these models do not take into account the accumulation of pore pressures or liquefaction. ${ }^{[7]}$

\section{Total displacements of the piles}

Fig. 12 presents the total pile displacements under the 1989 Loma Prieta earthquake for the three soil constitutive models.

According to the pile deflection shown in Fig 12, the total displacements at the base of the piles are small and are at about the same for all the models. Thereafter, these total displacements gradually increase until maximum values are reached in the upper part of the piles, and become different for the three models.

This is due to the fact that at depth, the piles are embedded in good soil (dense sand layer), able to take up the efforts of wharf and undergo small deformations during the earthquake. While in the dike embankment, liquefaction occurs and induces large deformations especially at the embankment top.

Analyzing the maximum total pile displacements, it can be noted that for the first three piles of the wharf and also for the batter piles, the maximum total displacements are reached at the piles head. For the other piles, the maximum total displacements are particularly localized at a height in the range of $20.2 \mathrm{~m}$ to $22.2 \mathrm{~m}$.

The largest of the maximum total displacements for the different piles of the wharf is observed for all models at the last pile (pile 7), caused by the significant deformation of loose sand at the top of the embankment, as shown in Fig. 6, 7 and 8. The values obtained are $0.139 \mathrm{~m}, 0.131 \mathrm{~m}$ and $0.077 \mathrm{~m}$ for the MC, HS and HSS models, respectively.

Comparing the results of this study with those of the numerical analysis using the finite difference method (Fig. 9, where the maximum pile displacement equals $0.08606 \mathrm{~m}$ ), the MC and HS models give a maximum total pile displacement overestimated by $61.51 \%$ and $52.2 \%$ respectively, while for the HSS model, the maximum total displacement is underestimated by $10.52 \%$.

It can be concluded that the results obtained with the HSS model are close to the results of numerical analysis conducted by Heidary-Torkamani et al., ${ }^{[28]}$ and the MC model results are larger than the results of advanced models (HS and HSS models). This is due to the fact that the MC model uses a constant Young modulus for soil and only Rayleigh damping, in contrast to the advanced models, which use three different types of stiffness modulus $\left(E_{50}^{\text {ref }}, E_{\text {oed }}^{r e f}\right.$ and $\left.E_{u r}^{r e f}\right)$. However, the HSS model is able to capture more realistic behavior of pilesupported wharf under earthquake, because it considers the reduction of soil stiffness with increasing shear strain amplitudes, and introduces hysteric material damping during seismic loading. ${ }^{[73]}$ 


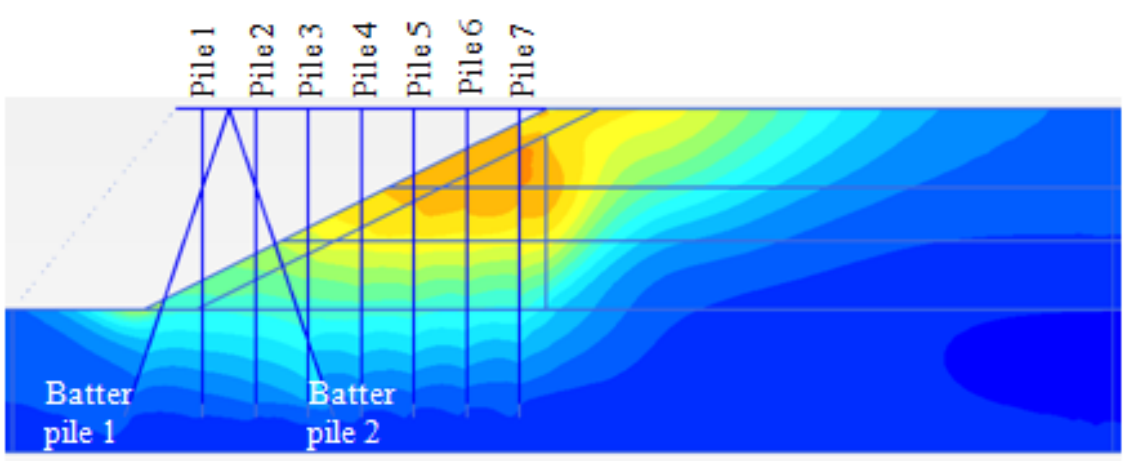

Figure 6: Total displacements with MC model.
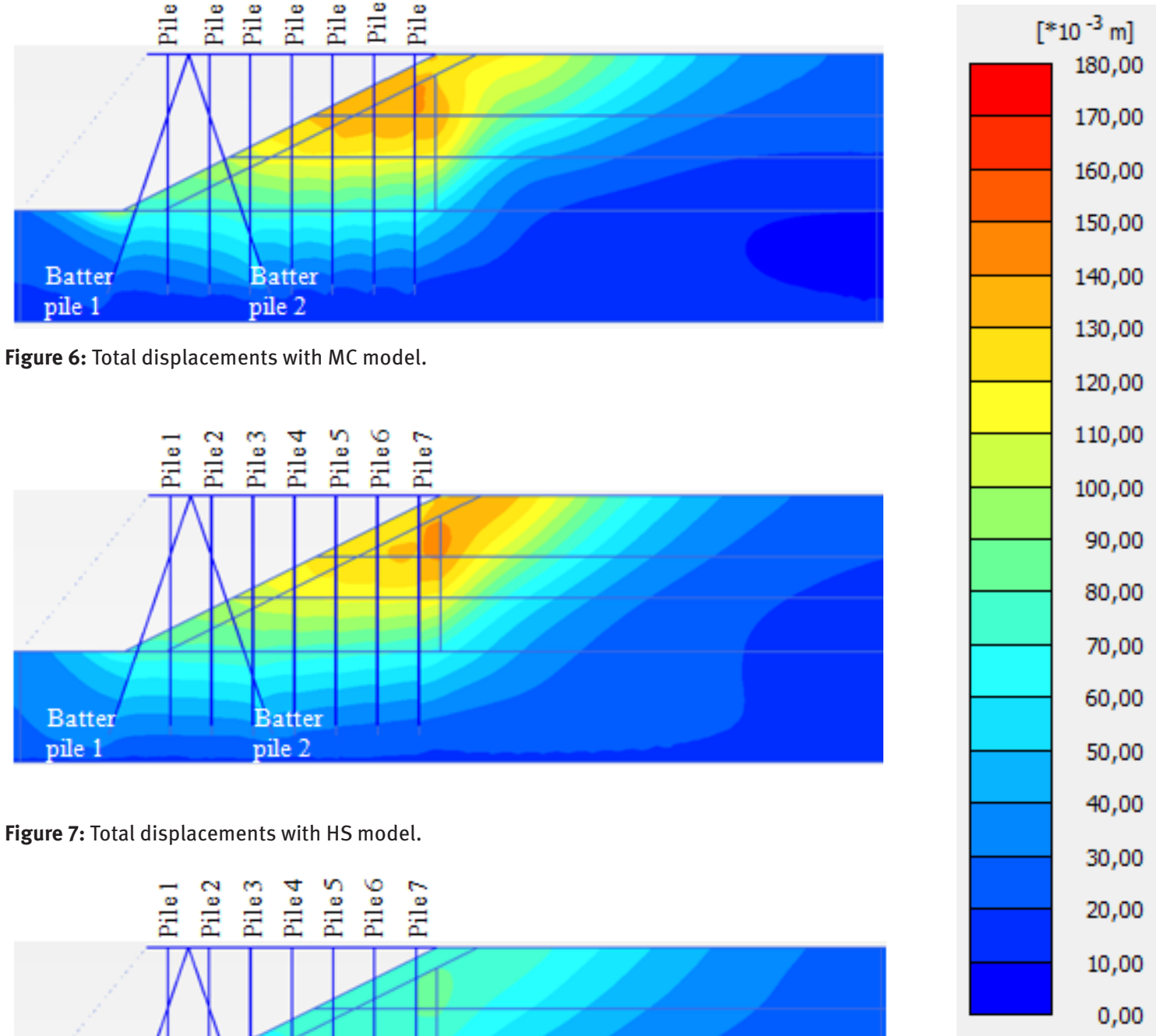

Figure 7: Total displacements with HS model.

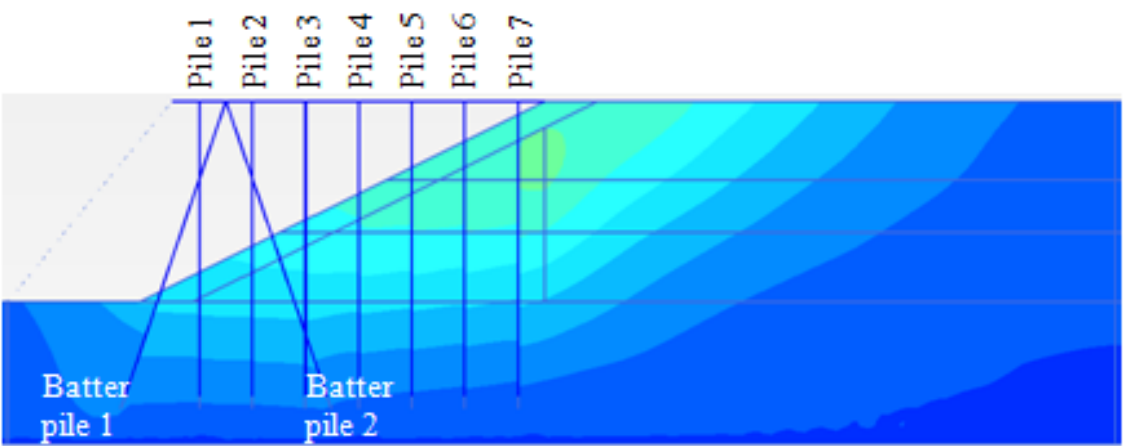

0,00

Figure 8: Total displacements with HSS model.

\section{Displacements at the top and at the toe of the rock dike}

Table 5 shows the displacement time histories at the top and at the toe of the cut-slope rock dike.

\subsection{At the top of the rock dike}

The top of the cut-slope rock dike undergoes a significant lateral displacement caused by the deformations of loose sand at the embankment top. The maximum lateral displacement calculated by MC and HS models is $89.77 \%$ and $46.59 \%$, respectively, higher than the result of HSS model.

At the end of seismic loading, the MC and HS models recorded a permanent lateral displacement of $85.5 \%$ and $65.21 \%$, respectively, higher than that obtained by the HSS model.

When looking at the vertical displacement of the dike top, the MC and HS models provide a maximum settlement of $135.29 \%$ and $52.94 \%$, respectively, larger 


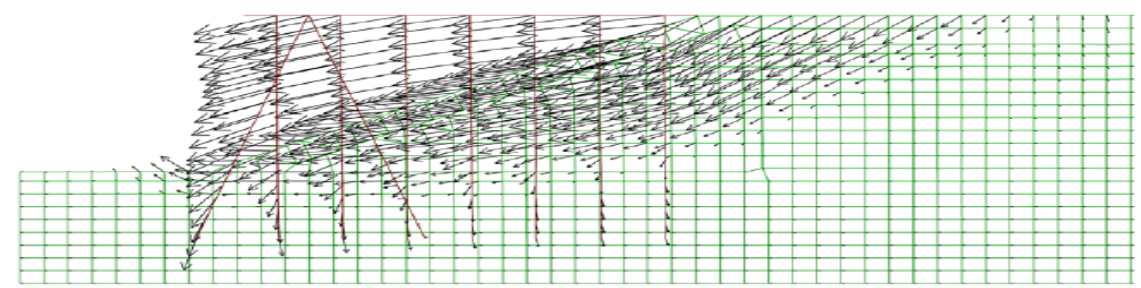

\section{Displacement vectors \\ Max Vector $=$ 8.973E-02}

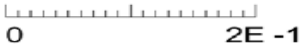

Pile Plot

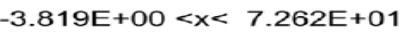

$-2.522 E+01<y<5.122 E+01$

Grid plot

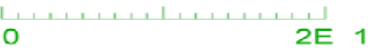

Structural Displacement

Max Value $=8.606 \mathrm{E}-\mathrm{O} 2$

Pile Plot: Structural displacement Max Value $=0.08606 \mathrm{~m}$

Figure 9: Nodal displacement vectors for the wharf supported piles $(\mathrm{m})^{[28]}$.
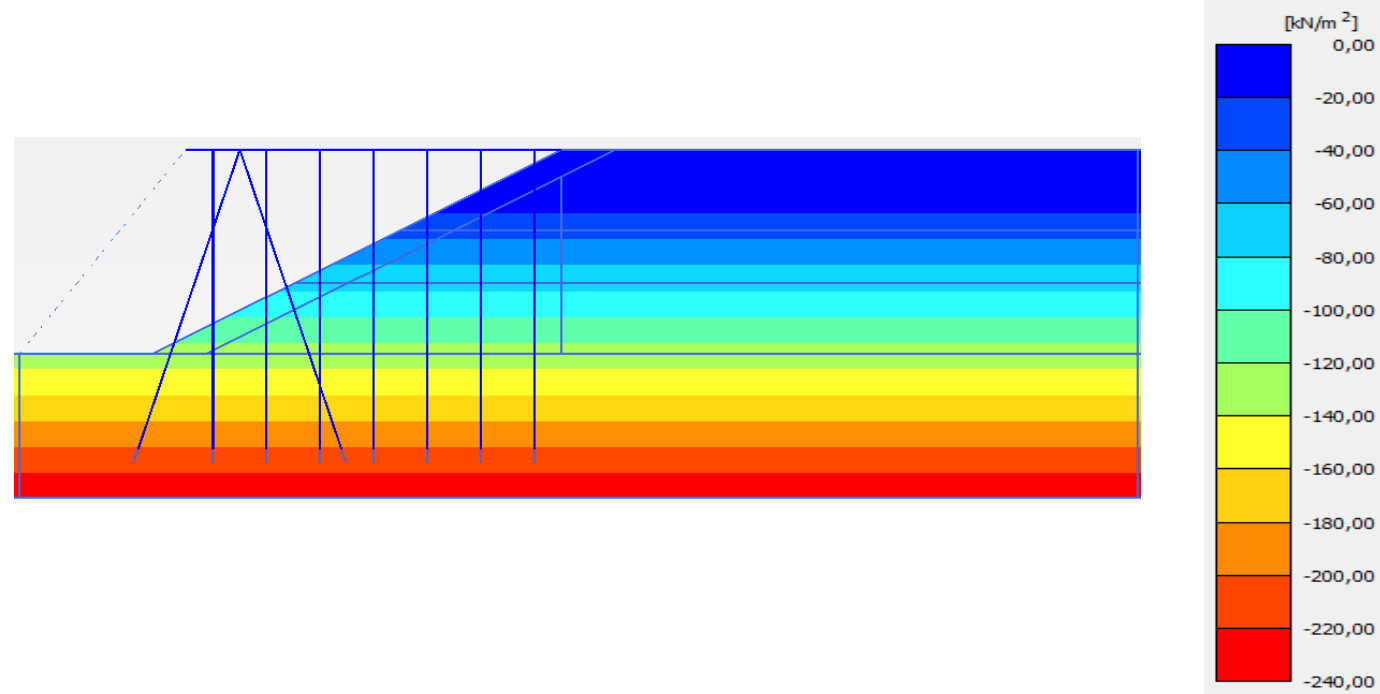

Figure 10: Pore pressure of the numerical model

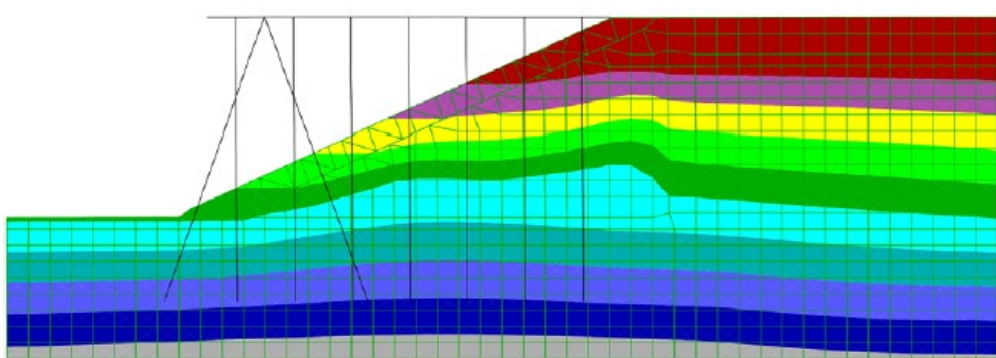

Contour interval $=2.50 \mathrm{E}+04$ Grid plot

0
$-3.819 \mathrm{E}+00<\mathrm{x}<7.262 \mathrm{E}+01$ $-2.522 \mathrm{E}+01<\mathrm{y}<5.122 \mathrm{E}+01$
Pore pressure contours

$0.00 \mathrm{E}+00$

$2.50 \mathrm{E}+04$

$5.00 \mathrm{E}+04$

$7.50 \mathrm{E}+04$

$1.00 \mathrm{E}+05$

$1.25 \mathrm{E}+05$

$1.50 \mathrm{E}+05$

$1.75 \mathrm{E}+05$

$2.00 \mathrm{E}+05$

$2.25 \mathrm{E}+05$

Figure 11: Total pore pressure contours $(\mathrm{Pa})^{[28]}$. 


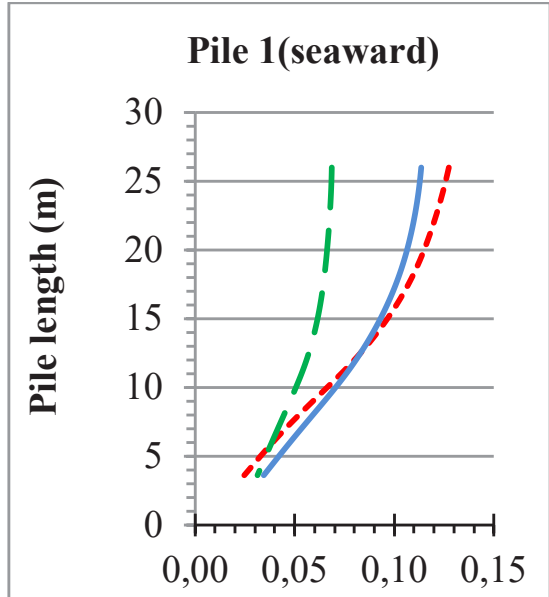

Total displacement (m)
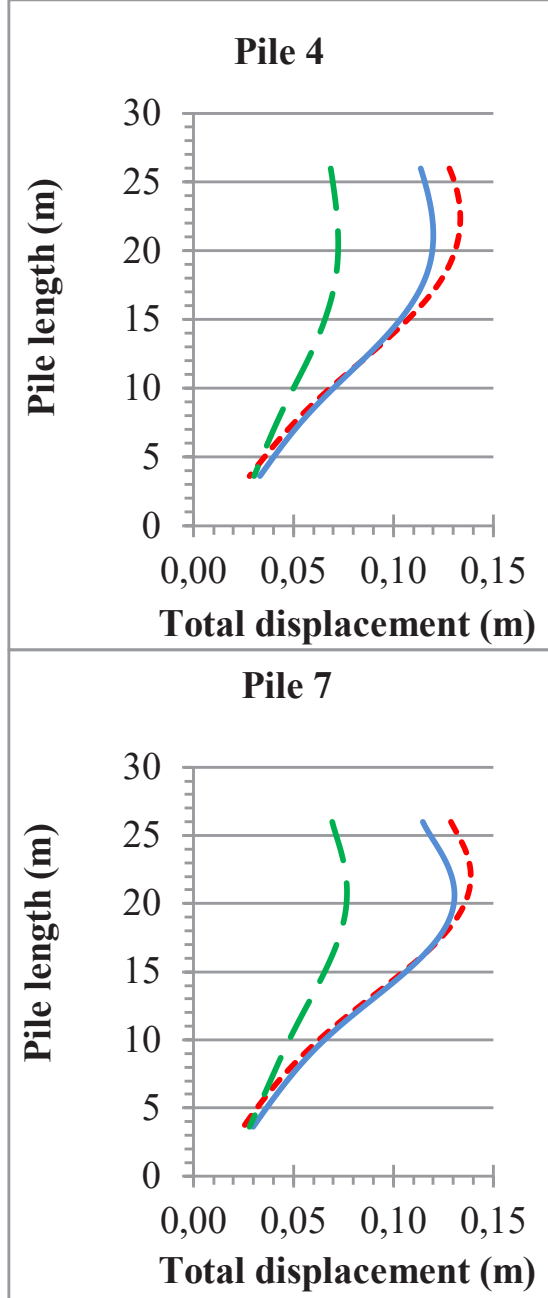

Pile 2

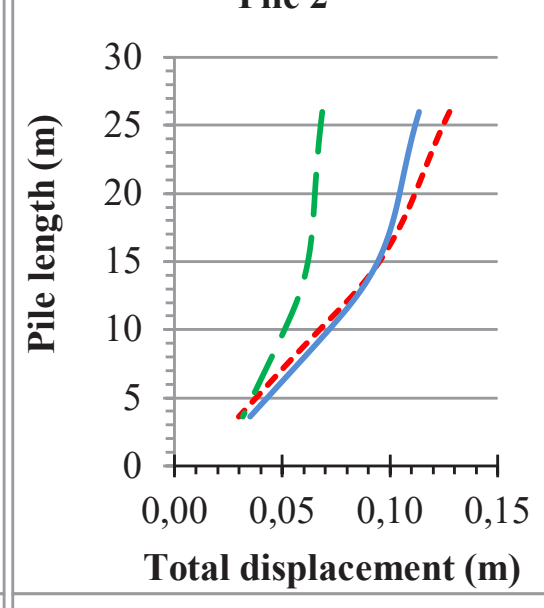

Pile 5

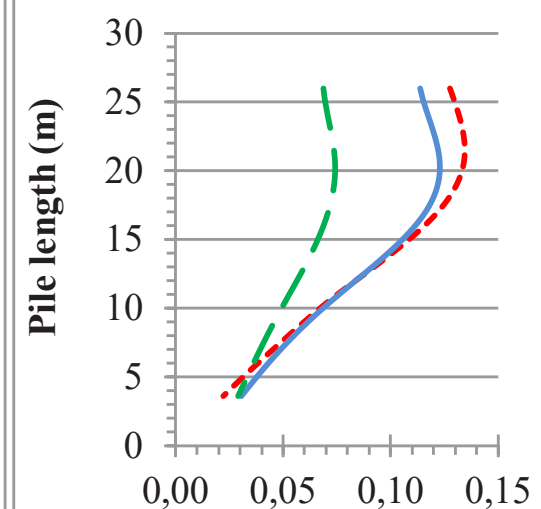

Total displacement $(\mathrm{m})$
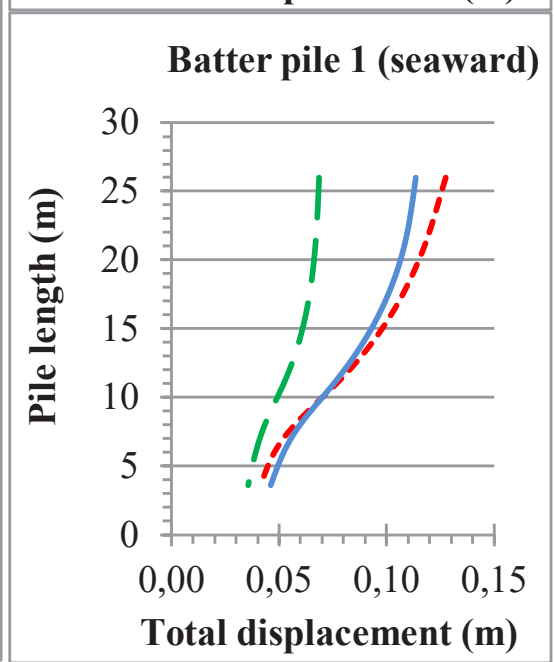

Pile 3

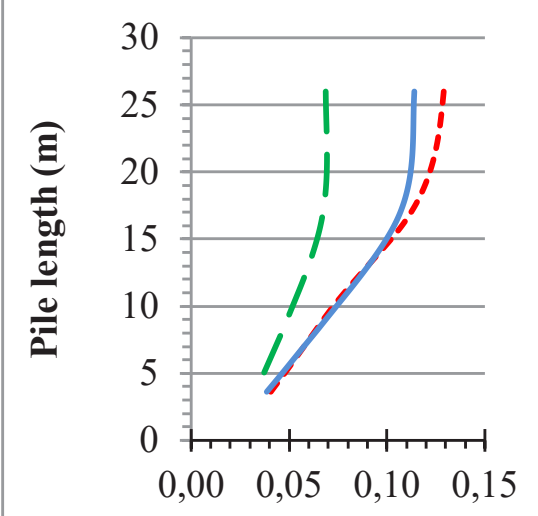

Total displacement (m)

Pile 6
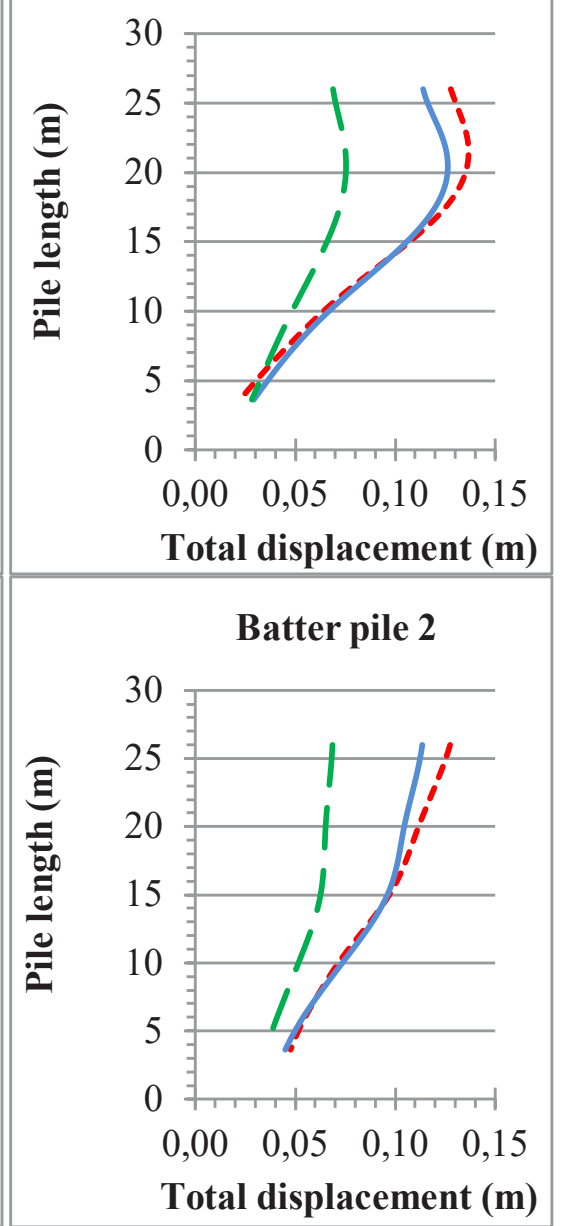

---- MC model

- HS model

- - HSS model

Figure 12: Total displacements of the piles. 
Table 5: Lateral and vertical displacement time histories at the top and at the toe of the rock dike.

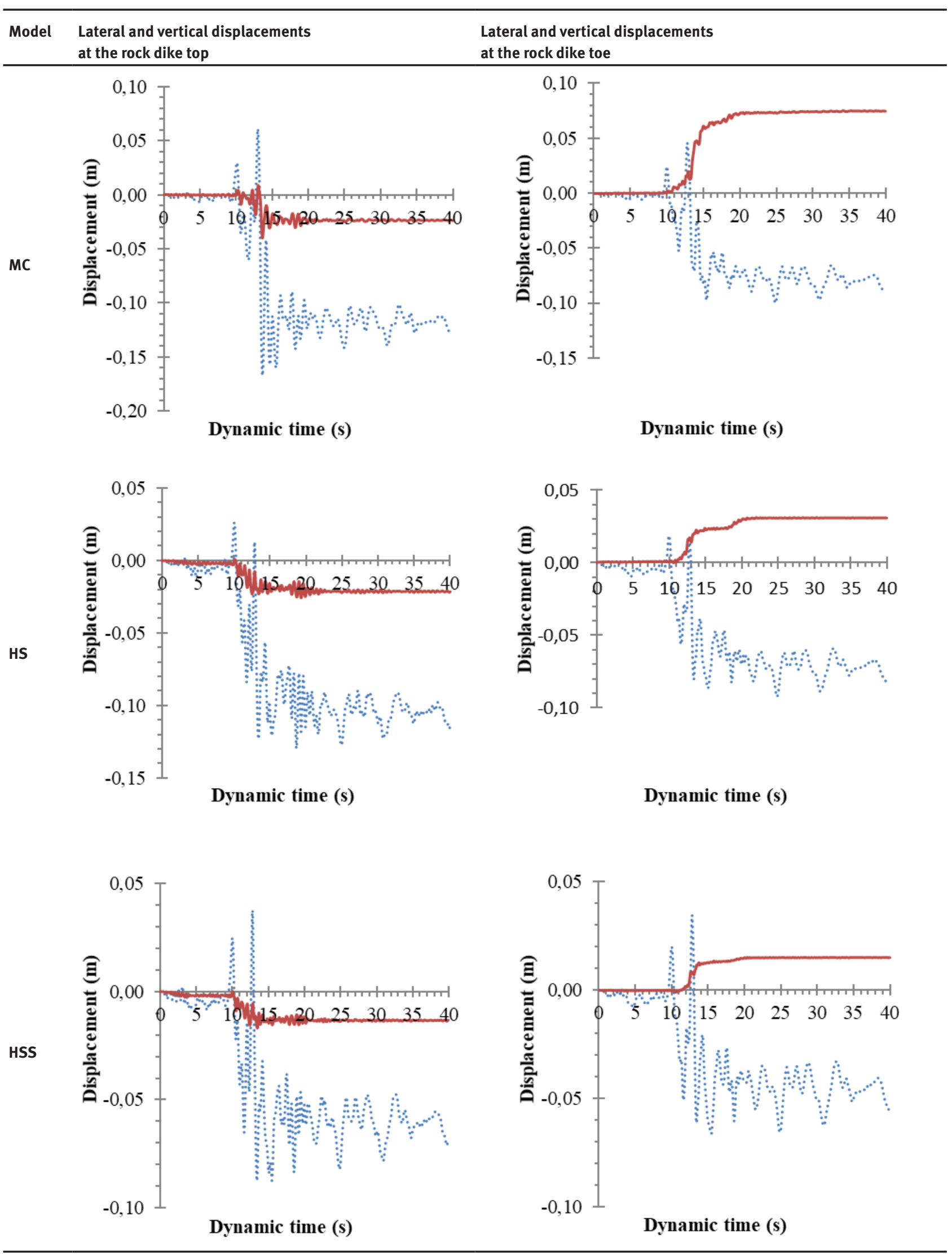


than that predicted by the HSS model. For the permanent vertical displacement, the results obtained with MC and HS models increase relative to HSS model by $84.61 \%$ and $61.53 \%$, respectively.

\subsection{At the toe of the rock dike}

Concerning the toe of the cut-slope rock dike during the earthquake, the MC and HS models have a maximum lateral displacement of $51.51 \%$ and $39.39 \%$, respectively, greater than in the HSS model. For the permanent lateral displacement, the MC and HS models recorded a result of $76 \%$ and $62 \%$, respectively, higher than that estimated by the HSS model.

It can be noted that the rock dike toe has a tendency to heave. The maximum vertical displacement time history calculated for MC, HS and HSS models are 0.075 $\mathrm{m}, 0.031 \mathrm{~m}$ and $0.015 \mathrm{~m}$, respectively, and occurred from the twentieth second during the earthquake loading. Beyond that time, the maximum vertical displacements stabilize. The MC and HS models give a maximum vertical displacement of $400 \%$ and $106.66 \%$, respectively, higher than that observed by the HSS model.

\subsection{Comparison of the displacements at the top and at the toe of the rock dike}

Comparing the lateral displacements of the dike top with those of its toe, it can be concluded that the top moves more than the toe of the dike by $67 \%, 40.21 \%$ and $33.33 \%$ for the maximum lateral displacement, and by $45.45 \%$, $40.74 \%$ and $38 \%$ for the permanent lateral displacement calculated with the MC, HS and HSS models, respectively. This difference is due to the significant deformation of the loose sand at the embankment top, as presented in Fig. 6 , 7 and 8.

Concerning the predicted vertical displacement, the rock dike top tends to settle contrary to its toe, which heaves.

It can also be noted, that all the results obtained at the top and at the toe of the rock dike using the MC and HS models are relatively higher than the HSS model results.

\section{Conclusion}

The two-dimensional finite element method was used to study the sensitivity of the seismic response of pilesupported wharf to the variation of the soil constitutive models. Indeed, three constitutive models with different accuracies were adopted for this analysis, namely the MC model, the HS and HSS advanced models.

The JCB01 model selected from a series of centrifuge models carried out at the Center for Geotechnical Modeling of California University (UC Davis) was chosen for the study. . $^{[3,10,26,28,29]}$

This model has a configuration of a typical wharf of Western United States ports. It consists of a deck supported by seven rows of vertical piles including two pairs of batter piles, embedded in cut slope rock dike overlaid an embankment of loose sand. The model was subjected to the 1989 Loma Prieta earthquake.

The wharf was modeled using the plane strain model. The concept of pseudo cohesion in rockfill was introduced. The analysis was carried out in time-domain and modification of the initial Newmark scheme defined with $\alpha$-method (or HHT method) ${ }^{[6]}$ was used. The constitutive parameters of soil were calibrated through numerical soil element tests.

In this work, the performance of numerical modeling in the estimation of wharf structural displacement and pore pressure were compared to the numerical results of Mohr Coulomb model in FLAC2D, carried out by HeidaryTorkamani et al. ${ }^{[28]}$ The verification shows that the model based on higher stiffness under small-strain (HSS model) comes closest to the results of Heidary-Torkamani et al. ${ }^{[28]}$ contrary to the MC and HS models.

This is due to the fact that the MC model considers a constant Young's modulus for soil and uses only Rayleigh damping, contrary to the advanced models (HS and HSS), which uses three different types of stiffness modulus $\left(E_{50}^{r e f}, E_{o e d}^{r e f}\right.$ and $\left.E_{u r}^{r e f}\right)$, in order to accurately predict the soil behavior. In addition, the HSS model takes into consideration the rigidity in small ground deformations. It includes two parameters $G_{0}$ ref and $\gamma_{0, p}$ and incorporates the hysteretic damping of materials in addition to Rayleigh damping.

The use of approximations from empirical equations developed by Hardin and Black ${ }^{[78]}$ in order to determinate $G_{0}$ parameter for HSS model, gives appropriate result.

The displacement of piles in sloping rockfill and the displacement time histories of the rock dike at the top and at the toe were also highlighted. It can be observed that the earthquake induced significant lateral movement at the top of the cut-slope rock dike, due to deformations at the upper part of the embankment during the liquefaction of loose sand. This lateral ground displacement affects the behavior of the wharf and the displacement of piles, specially the piles closest to the top of the rock dike. 
At the base of the piles, the total displacements are small, and then gradually increase until reaching maximum values at the top of the first three piles (seaward) as well as for the batter piles. But for the other piles, the maximum values of the total displacement are reached at the upper part of the piles when deformation of loose sand is important. It can be also seen that the batter piles have performed adequately.

According to the analysis results, the MC and HS models overestimate the maximum total displacement in piles by $61.51 \%$ and $52.2 \%$, respectively, whereas for the HSS model, the maximum total displacement is underestimated by $10.52 \%$, relative to the result of the numerical analysis established with the finite difference method. ${ }^{[28]}$

The displacement time history at the dike top is greater than its displacement at the toe due to lateral movement at the embankment top. A difference of about $67 \%$, $40.21 \%$ and $33.33 \%$ is recorded for the maximum lateral displacement for MC, HS and HSS models, respectively, and a difference of about $45.45 \%, 40.74 \%$ and $38 \%$ is estimated regarding its permanent lateral displacement for MC, HS and HSS models, respectively. Concerning predicted vertical displacement, the top of the rock dike has a tendency to settle contrary to its toe, which heaves.

The influence of the soil constitutive models used in this study is demonstrated on the results of piles and cutslope rock dike displacements. It is concluded that the MC model is not appropriate for modeling seismic behavior of pile-supported wharf structures, and it is recommended to use an advanced model with nonlinear behavior under small-strain and hysteretic damping.

The response of the piles embedded into the rock dike is dictated by the resulting soil deformation mechanisms. The choice of the appropriate soil constitutive model has significant effects on the numerical results, and depends on many factors related to the type of analysis to perform, expected precision of predictions and available soil parameters.

The use of 2D finite element analysis with planestrain and HSS model is an efficient tool for predicting the seismic behavior of pile-supported wharf. However, some suggestions and perspectives have emerged from this work. First, it would be interesting to use a model better suited to liquefaction analysis and allowing to determine the generation of excessive pore pressure during an earthquake (such as the UBCsand model), and to compare its results with those obtained in this paper.

Secondly, it can be noticed that the use of complex soil constitutive model (as advanced models) is computationally expensive, especially in dynamic calculation. And in order to remedy this, it is advisable to use adaptive constitutive modeling. That can considerably reduce the computational effort. This approach consists of using different soil constitutive models with different levels of complexity, but from the same hierarchical soil model family. Then, more sophisticated models are assigned to the regions that are directly influenced by the geotechnical problem. On the other hand, simpler models are assigned to other regions with low concentration of stress and strain. Lastly, it will be interesting to evaluate and to compare the results of this work with advanced 3D finite element analysis, focusing on the differences between the two methods.

\section{Reference}

[1] D. Yang, Deformation-Based Seismic Design Models for Waterfront Structures, PhD Thesis, Oregon State University, 1999.

[2] Itasca, FLAC User's Manual for version 4.0. Itasca Consulting Group, Inc. Minneapolis: Minnesota, USA, 2000.

[3] N. J. McCullough, The seismic geotechnical modeling, performance, and analysis of pile-supported wharves, PhD Thesis, Oregon State University, 2003.

[4] L. D. Suits, T. C. Sheahan, N. J. McCullough, S. Dickenson, Centrifuge seismic modeling of pile-supported wharves. Geotechnical Testing Journal 30(5), 2007. DOI: 10.1520/ GTJ14066

[5] J. C. Boland, S. M. Schlechter, N. J. McCullough, S. E. Dickenson, B. L. Kutter, D. W. Wilson, Data Report: PileSupported Wharf Centrifuge Model (SMS02). Geotechnical Engineering Group, Department of Civil, Construction and Environmental Engineering, Oregon State University, 2001a.

[6] N. J. McCullough, S. M. Schlechter, S. E. Dickenson, B. L. Kutter, D. W. Wilson, Data Report: Pile-Supported Wharf Centrifuge Model (NJM01). Geotechnical Engineering Group, Department of Civil, Construction and Environmental Engineering, Oregon State University, 2000.

[7] S. M. Schlechter, N. J. McCullough, S.E. Dickenson, B. L. Kutter, D. W. Wilson, Data Report: Pile-Supported Wharf Centrifuge Model (NJM02). Geotechnical Engineering Group, Department of Civil, Construction and Environmental Engineering, Oregon State University, 2000a.

[8] S. M. Schlechter, N. J. McCullough, S. E. Dickenson, B. L. Kutter, D. W. Wilson, Data Report: Pile-Supported Wharf Centrifuge Model (SMS01). Geotechnical Engineering Group, Department of Civil, Construction and Environmental Engineering, Oregon State University, 2000b.

[9] N. J. McCullough, S. E. Dickenson, S. M. Schlechter, The seismic performance of piles in waterfront applications. Ports Conference 2001, Norfolk, Virginia, United States, April 29-May 2, 2001, pp. 1-10.

[10] J. C. Boland, S. M. Schlechter, N. J. McCullough, S.E. Dickenson, B. L. Kutter, D. W. Wilson, Data Report: Pile-Supported Wharf Centrifuge Model (JCB01). Geotechnical Engineering 
Group, Department of Civil, Construction and Environmental Engineering, Oregon State University, 2001b.

[11] J. I. Hwang, S. R. Kim, J. H. Kim, M. M. Kim, Seismic responses of geotechnical port and harbor structures by the shaking table test. KEERC-MAE Joint Seminar on Risk Mitigation for Regions of Moderate Seismicity, University of Illinois at UrbanaChampaign, August 5-8, 2001.

[12] S. E. Dickenson, N. J. McCullough, Modeling the Seismic Performance of Pile Supported Foundations for Port and Coastal Infrastructure. Workshop on Seismic Performance and Simulation of Pile Foundations in Liquefied and Laterally Spreading Ground, ASCE 2006, University of California, Davis, California, United States, March 16-18, 2005, pp.173-191. https://doi.org/10.1061/40822(184)15

[13] N. M. Newmark, Effects of earthquakes on dams and embankments. Geotechnique 15. 2 (1965) 139-160.

[14] J. A. Egan, R. F. Hayden, L. L. Scheibel, M. Otus, G. M. Serventi, Seismic Repair at Seventh Street Marine Terminal. In: Proceedings of the conference Grouting, Soil Improvement, and Geosynthetics, ASCE Geotechnical Special Publication, No. 30, Vol. 2, New Orleans: Louisiana, February 25-28, 1992.

[15] J. P. Singh, M. Tabatabaie, J. B. French, Geotechnical and Ground Motion Issues in Seismic Vulnerability Assessment of Existing Wharf Structures. In: Proceedings of the ASCE Ports 2001 Conference, Norfolk, Virginia, April 29-May 2, 2001.

[16] A. Takahashi, J. Takemura, Liquefaction-induced large displacement of pile-supported wharf. Soil Dynamics and Earthquake Engineering 25 (2005) 811-825. doi:10.1016/j. soildyn.2005.04.010

[17] S. Dickenson, S. Yang, D. Schwarm, M. Rees, Seismic performance analysis of pile-supported wharves subjected to long-duration ground motions. Edited by Moh Huang, Proceedings of SMIP14: Seminar on Utilization of StrongMotion Data, October 9, 2014, pp. 63-82.

[18] J. C. Huertas, C. Romanel, Seismic performance of a wharf dyke. Computer Methods and Recent Advances in Geomechanics - Oka, Murakami, Uzuoka \& Kimoto (Eds.), Taylor \& Francis Group, London, 2015, pp. 779-784.

[19] S. Dickenson, S. Yang, D. Schwarm, M. Rees, Design considerations for the kinematic loading of piles. 14th Triennial International Conference, New Orleans, LA, ASCE 2016, June 12-15, 2016, pp. 1-10. https://doi. org/10.1061/9780784479902.022

[20] L. Su, J. Lu, A. Elgamal, A. K. Arulmoli, Seismic performance of a pile-supported wharf: Three-dimensional finite element simulation. Soil Dynamics and Earthquake Engineering 95 (2017) 167-179. DOI: 10.1016/j.soildyn.2017.01.009

[21] M. Souri, A. Khosravifar, S. E. Dickenson, S. Schlechter, N. J. McCullough, Inertial and liquefaction-induced kinematic demands on a pile-supported wharf: physical modeling. () ASCE. Geotechnical Earthquake Engineering and Soil Dynamics V GSP 292, 2018, pp. 388-396.

https://doi.org/10.1061/9780784481479.040

[22] A. Vytiniotisa, A.-I., Panagiotidoub, A. J. Whittlec, Analysis of seismic damage mitigation for a pile-supported wharf structure. Soil Dynamics and Earthquake Engineering 119 (2019) 21-35. https://doi.org/10.1016/j.soildyn.2018.12.020

[23] J. S. Chiou, C. H. Chiang , H. H. Yang, S. Y. Hsu, Developing fragility curves for a pile-supported wharf. Soil Dynamics and
Earthquake Engineering 31 (2011) 830-840. doi:10.1016/j. soildyn.2011.01.011

[24] A. Gheris, A. Hamrouni, Treatment of an expansive soil using vegetable (DISS) fibre. Innovative Infrastructure Solutions, 2020, 5: 34 DOI: 10.1007/s41062-020-0281-5

[25] R. Amirabadi, K. Bargi, H. Heidary-Torkamani, Seismic demands for pile-supported wharf. Structures with batter piles. Research Journal of Applied Sciences, Engineering and Technology 4(19) (2012) 3791-3800.

[26] R. Amirabadi, K. Bargi, M. Dolatshahi Piroz, H. HeidaryTorkamani, N. J. Mccullough, Determination of optimal probabilistic seismic demand models for pile-supported wharves. Structure and Infrastructure Engineering: Maintenance, Management, Life-Cycle Design and Performance. Vol. 10, No. 9, (2014) 1119-1145. http://dx.doi.org $/ 10.1080 / 15732479.2013 .793723$

[27] H. Heidary-Torkamani, K. Bargi, R. Amirabadi, Fragility curves derivation for a pile-supported wharf. International Journal Of Maritime Technology. IJMT Vol.1. No. 1, Spring \& Summer 2013, pp. 1-10. http://ijmt.ir/browse.php?a_code=A-10-236$1 \&$ sid=1\&slc_lang $=e n$

[28] H. Heidary-Torkamani, K. Bargi, R. Amirabadi, N. J. McCllough, Fragility estimation and sensitivity analysis of an idealized pile-supported wharf with batter piles. Soil Dynamics and Earthquake Engineering 61-62 (2014a) 92-106. http://dx.doi. org/10.1016/j.soildyn.2014.01.024

[29] H. Heidary-Torkamani, K. Bargi, R. Amirabadi, Seismic vulnerability assessment of pile-supported wharves using fragility curves. Structure and Infrastructure Engineering: Maintenance, Management, Life- Cycle Design and Performance. Vol. 10, No. 11, (2014b) 1417-1431. http://dx.doi. org/10.1080/15732479.2013.823453

[30] A. Hamrouni, D. Dias, B. Sbartai, Reliability analysis of shallow tunnels using the response surface methodology. Underground Space, 2017, 2(4): 246-258.

[31] W.H. Roth, H. Fong, C. Rubertis, Batter piles and the seismic performance of pile-supported wharves. Proceedings of Ports'92, ASCE, Seattle, WA, 1992, pp. 336-349.

[32] S. M. Schlechter, S. E. Dickenson, N. J. McCullough, J. C. Boland, Influence of batter piles on the dynamic behavior of pile-supported wharf structures. Ports Conference 2004, ASCE 2004, pp. 1-10. DOI: 10.1061/40727(2004)12

[33] S. A. Razavi, A. Fakher, S. R. Mirghaderi, An insight into the bad reputation of batter piles in seismic performance of wharves. 4th International Conference on Earthquake Geotechnical Engineering. Paper $\mathrm{N}^{\circ}$ 1423, 2007, pp. 1-10.

[34] J. Li, B. Song, J. Cui, Seismic dynamic damage characteristics of vertical and batter pile-supported wharf structure systems. Journal of Engineering Science and Technology Review 8 (5) (2015) 180-189. DOI: 10.25103/jestr.085.23

[35] J. Li, B. Song, P. Wu, Comparative study of seismic dynamic damage on vertical and batter pile-supported wharf structures. Journal of Building Structures. Vol. 37, No. 7, (2016) 151-157. DOI: 10.14006/j.jzjgxb.2016.07.019

[36] J. H. Atkinson, G. Sallfors, Experimental determination of soil properties. General Report to Session 1. Proceedings of the $10^{\text {th }}$ ECSMFE, Florence 3, 1991, pp. 915-956.

[37] A. Truty, Hardening Soil Model with Small Strain Stiffness. ZACE Services, 2008. 
[38] A Hamrouni, D Dias, B Sbartai .Probability analysis of shallow circular tunnels in homogeneous soil using the surface response methodology optimized by a genetic algorithm. Tunnell Undergr Space Technol (2019) 86:22-33

[39] T. Benz, R. Schwab, P. Vermeer, Small-strain stiffness in geotechnical analyses. Bautechnik Special issue $2009-$ Geotechnical Engineering, 2009, pp.16-27. DOI: 10.1002/ bate. 200910038

[40] R. Obrzud, The Hardening Soil model with small strain stiffness. GeoMod SA, 2011.

[41] F. Besseling, Soil-structure interaction modelling in performance based seismic jetty design, Final report. M.Sc. Graduation Project, Delft University of Technology, 2012.

[42] K. N. Vakili, T. Barciaga, A. A. Lavasan, T. Schanz, A practical approach to constitutive models for the analysis of geotechnical problems. The Third International Symposium On Computational Geomechanics (ComGeo III), at Krakow, Poland, Volume: 1, August 2013, pp. 738-749.

[43] K. N. Vakili, A.A. Lavasan, M. Datcheva, T. Schanz, The influence of the soil constitutive model on the numerical assessment of mechanized tunneling. Numerical Methods in Geotechnical Engineering contains the proceedings of the 8th European Conference on Numerical Methods in Geotechnical Engineering (NUMGE 2014), Delft, The Netherlands, 18-20 June 2014, pp. 889-894. DOI: 10.1201/b17017-158

[44] M. A. Op de Kelder, 2D FEM analysis compared with the in-situ deformation measurements: A small study on the performance of the HS and HSsmall model in a design. Plaxis Bulletin, Issue 38 /Autumn 2015, pp. 10-17.

[45] I. Alpan, The geotechnical properties of soils. Earth-Science Reviews, Vol. 6, 1970, pp. 5-49.

[46] T. Benz, P. A. Vermeer, Zuschrift zum Beitrag "Uber die Korrelation der odometrischen und der "dynamischen" Steifigkeit nichtbindiger Boden"von T. Wichtmann und Th. Triantafyllidis (Bautechnik 83, No. 7, 2006), Bautechnik, Vol. 84 (5), 2007, pp. 361-364.

[47] T. Wichtmann, T. Triantafyllidis, On the correlation of "static" and "dynamic" stiffness moduli of non-cohesive soils. Bautechnik Special issue 2009 - Geotechnical Engineering, 2009, pp. 28-39. DOI: 10.1002/bate.200910039

[48] Á. Szerző, L. Batali, Numerical modelling of piled raft foundations. Modelling particularities and comparison with field measurements. Proceedings of the 19th International Conference on Soil Mechanics and Geotechnical Engineering, Seoul, 2017, pp. 3055-3058.

[49] H. G. Poulos, Practical design procedures for piled raft foundations. J.A. Hemsley (ed.), Design Applications of Raft Foundations, Thomas Telford, London, 2000, pp. 425-468.

[50] M. F. Randolph, Piglet - Analysis and design of pile groups, version 5.1, July 2006.

[51] A. Akbari Hamed, Predictive numerical modeling of the behavior of rockfill dams. Master's thesis, Ecole de technologie supérieure, Montréal, 2017.

[52] N. Yeganeh, B. Fatahi, Effects of choice of soil constitutive model on seismic performance of moment-resisting frames experiencing foundation rocking subjected to near-field earthquakes. Soil Dynamics and Earthquake Engineering 121 (2019) 442-459. https://doi.org/10.1016/j. soildyn.2019.03.027
[53] PLAXIS 2D, Finite Element Code for Soil and Rock Analyses. PLAXIS BV, Delft, The Netherlands, 2010.

[54] A Hamrouni, B Sbartai, D Dias. Probabilistic analysis of ultimate seismic bearing capacity of strip foundations. Journal of Rock Mechanics and Geotechnical Engineering, 2018, 10(4): 717-724

[55] J. Lysmer, R. L. Kuhlmeyer, Finite Dynamic Model for Infinite Media. ASCE Journal of Engineering and Mechanical Division, 1969, pp. 859-877.

[56] PLAXIS 2D, Reference Manual, 2010, pp. 1-270.

[57] R. L. Kuhlemeyer, J. Lysmer, Finite element method accuracy for wave propagation problems. Journal of the Soil Mechanics and Foundations Division, ASCE, Vol. 99, No. SM5, 1973, pp. 421-427.

[58] O. C. Zienkiewicz, R. L. Taylor, The finite element method - Solid and fluid mechanics, Dynamics and Non-Linearity. Fourth edition, Vol. 2, McGraw-Hill Book Company Europe, London, 1991.

[59] T. J. R. Hughes, The finite element method: Linear static and dynamic finite element analysis. Prentice-Hall, INC., Englewood Cliffs, New Jersey, 1987, pp. 1-704.

[60] PLAXIS 2D, Scientific Manual. 2010, pp. 1-64.

[61] LUSAS, Theory Manual, FEA Ltd. United Kingdom, 2000.

[62] A Hamrouni, D Dias, B Sbartai. Reliability analysis of a mechanically stabilized earth wall using the surface response methodology optimized by a genetic algorithm. Geomechanics and Engineering, 2018, 15(4): 937-945

[63] A. Laera, R. B. J. Brinkgreve (editors), PLAXIS 2015:

Site response analysis and liquefaction evaluation. The Netherlands, 2015a, pp. 1-42.

[64] A. Laera, R. B. J. Brinkgreve (editors), PLAXIS 2015: Ground response analysis in PLAXIS 2D. The Netherlands, 2015b, pp. 1-46.

[65] K. Arulmoli, K. K. Muraleetharan, M. M. Hossain, L. S. Fruth, VELACS: Verification of liquefaction analyses by centrifuge studies laboratory testing program soil data report. Prepared for: National Science Foundation, The Earth Technology Corporation, Project No. 90-0562, Irvine, CA., 1992, pp. 1-394.

[66] A Hamrouni, D Dias, B Sbartai (2020) Soil spatial variability impact on the behaviour of a reinforced earth wall. Front Struct Civ Eng 14, 518-531 https://doi.org/10.1007/s11709-020-0611-x

[67] G. M. Diaz, B. W. Patton, G. L. Armstrong, M. Joolazadeh, Lateral Load Tests of Piles in Sloping Rock Fill. Proceedings of a Symposium on the Analysis and Design of Pile Foundations. ASCE National Convention, San. Francisco, California, October 1-5, 1984, pp. 214-231.

[68] G. Martin, Port of Los Angeles Seismic Code: Presentation on Geotechnical Aspects. Proceedings POLA Container Wharf Seismic Code Workshop, Los Angeles, September 13, 2005.

[69] N. J. McCullough, S. E. Dickenson, The behavior of piles in sloping rock fill at marginal wharves. Ports Conference 2004, ASCE 2004, Houston, Texas, United States, May 23-26, 2004, pp. 1-10. https://doi.org/10.1061/40727(2004)86

[70] Y. Kawamata, Seismic performance of pile-supported container wharf structures in rockfill. PhD diss., Oregon State University, 2009.

[71] PLAXIS 2D, Material Models Manual. 2010, pp. 1-188.

[72] T. Schanz, P. A. Vermeer, P. G. Bonnier, The hardeningsoil model: Formulation and verification. Beyond 2000 in 
Computational Geotechnics, Balkema: Rotterdam, 1999, pp. 281-290.

[73] R. B. J. Brinkgreve, M. H. Kappert, P. G. Bonnier, Hysteretic damping in a small-strain stiffness model. Numerical Models in Geomechanics - NUMOG X - Pande \& Pietruszczak (editors) ( 2007 Taylor \& Francis Group., London, 2007, pp. 737-742. DOI: 10.1201/NOE0415440271.ch106

[74] T. Benz, Small-strain stiffness of soils and its numerical consequences. PhD Thesis, Institute of Geotechnical Engineering, Universitat Stuttgart, 2007.

[75] R. L. Kondner, Hyperbolic Stress-Strain Response: Cohesive Soils. Journal of Soil Mechanics and Foundations Division. ASCE, Vol.89, No. SM1, In Proc., Paper 3429, 1963, pp. 115-143.

[76] R. J. Mair, Developments in geotechnical engineering research: applications to tunnels and deep excavations. Unwin Memorial Lecture 1992, Proc. Instn Civ. Engrs Civ. Engng, 3, 1993, pp. 27-41.

[77] J. H. Atkinson, Non-linear soil stiffness in routine design. Géotechnique 50, No. 5, 2000, pp. 487-508. https://doi. org/10.1680/geot.2000.50.5.487

[78] B. O. Hardin, W. L. Black, Sand stiffness under various triaxial stresses. Journal of the Soil Mechanics and Foundations Division, ASCE, 92(SM2), 1966, pp. 27-42.

[79] M. Vucetic, R. Dobry, Effect of soil plasticity on cyclic response. Journal of Geotechnical Engineering. Vol. 117, No. 1, January 1991, pp. 89-107.

[80] B. O. Hardin, V. P. Drnevich, Shear modulus and damping in soils: Design equations and curves. Proc. ASCE: Journal of the Soil Mechanics and Foundations Division, 98(SM7), 1972, pp. 667-692.

[81] K. Ishihara, Soil Behaviour in Earthquake Geotechnics. Oxford Engineering Science Series, Oxford University Press, United States, 1996.

[82] A Hamrouni, D Dias, B Sbartai. Probabilistic analysis of a piled earth platform under a concrete floor slab. Soils Found. 2017, 57 (5): 828-839

[83] W. A. Prakoso, F. H. Kulhawy, Contribution to piled raft foundation design. Journal of Geotechnical and Geoenvironmental Engineering, Vol. 127, No. 1, Paper No. 21503, 2001, pp. 17-24.

[84] A. Waruwu, H. C. Hardiyatmo, A. Rifa'l, Deflection behavior of the nailed slab system-supported embankment on peat soil. Journal of Applied Engineering Science 15(2017)4, 488, pp. 556-563. DOI:10.5937/jaes15-15113 